\title{
Development of a high spectral resolution surface albedo product for the ARM Southern Great Plains central facility
}

\author{
S. A. McFarlane ${ }^{1}$, K. L. Gaustad ${ }^{1}$, E. J. Mlawer ${ }^{2}$, C. N. Long ${ }^{1}$, and J. Delamere ${ }^{2}$ \\ ${ }^{1}$ Pacific Northwest National Laboratory, Richland, WA, USA \\ ${ }^{2}$ Atmospheric and Environmental Research Inc., Lexington, MA, USA
}

Received: 22 April 2011 - Published in Atmos. Meas. Tech. Discuss.: 24 May 2011

Revised: 4 August 2011 - Accepted: 22 August 2011 - Published: 1 September 2011

\begin{abstract}
We present a method for identifying dominant surface type and estimating high spectral resolution surface albedo at the Atmospheric Radiation Measurement (ARM) facility at the Southern Great Plains (SGP) site in Oklahoma for use in radiative transfer calculations. Given a set of 6-channel narrowband visible and near-infrared irradiance measurements from upward and downward looking multi-filter radiometers (MFRs), four different surface types (snow-covered, green vegetation, partial vegetation, non-vegetated) can be identified. A normalized difference vegetation index (NDVI) is used to distinguish between vegetated and non-vegetated surfaces, and a scaled NDVI index is used to estimate the percentage of green vegetation in partially vegetated surfaces. Based on libraries of spectral albedo measurements, a piecewise continuous function is developed to estimate the high spectral resolution surface albedo for each surface type given the MFR albedo values as input. For partially vegetated surfaces, the albedo is estimated as a linear combination of the green vegetation and non-vegetated surface albedo values. The estimated albedo values are evaluated through comparison to high spectral resolution albedo measurements taken during several Intensive Observational Periods (IOPs) and through comparison of the integrated spectral albedo values to observed broadband albedo measurements. The estimated spectral albedo values agree well with observations for the visible wavelengths constrained by the MFR measurements, but have larger biases and variability at longer wavelengths. Additional MFR channels at $1100 \mathrm{~nm}$ and/or $1600 \mathrm{~nm}$ would help constrain the high resolution spectral albedo in the near infrared region.
\end{abstract}

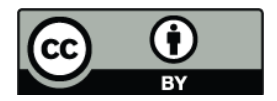

Correspondence to: S. A. McFarlane (sally.mcfarlane@pnl.gov)

\section{Introduction}

Radiative closure calculations, in which radiative transfer model calculations are compared to irradiance (flux) or radiance measurements, can serve as a testbed to evaluate the specification of atmospheric column properties retrieved from measurements (including surface conditions, water vapor amount, and aerosol and cloud properties), radiative transfer model calculations, and the radiative measurements themselves (e.g., Michalsky et al., 2006; McFarlane and Evans, 2004; Turner et al., 2004; Halthore and Schwartz, 2000; Mlawer et al., 2000). Previously, studies using data from the Atmospheric Radiation Measurement (ARM) Program have performed such comparisons in the longwave spectral region to refine treatment of the longwave water vapor continuum and to improve the specification of the atmospheric water vapor column. Through these closure studies, the uncertainty in calculated, clear-sky longwave irradiances at the surface has been reduced to less than $2 \mathrm{Wm}^{-2}$ for the range of measured precipitable water vapor values (Turner et al., 2004). The ARM community is now pursuing similar closure studies of broadband and spectral measurements in the shortwave to evaluate retrieved cloud and aerosol properties and to improve understanding of the shortwave spectral region.

Accurate modeling of atmospheric radiative transfer requires specification of all radiatively important input parameters including surface albedo, the fraction of incident solar irradiance reflected by the Earth's surface. Surface albedo of land surfaces varies spectrally, with vegetated surfaces having different spectral shapes than bare soil (Liang et al., 2002). Additionally, surface albedo varies temporally, both diurnally as solar zenith angle and cloud cover change and seasonally as vegetation characteristics change (Henderson-Sellers and Wilson, 1983). For some radiative

Published by Copernicus Publications on behalf of the European Geosciences Union. 
transfer applications, specification of a daily-averaged broadband albedo may be sufficient, but in other cases, specification of temporally and spectrally resolved surface albedo is needed. Previous studies have indicated that even in broadband closure studies, use of a spectrally resolved albedo can impact calculated diffuse irradiances due to the fact that atmospheric constituents such as aerosol, molecules, and water vapor have spectrally dependent scattering and absorption properties (Michalsky et al., 2003). For spectral closure studies, spectrally resolved surface albedo is even more critical.

There are few available data products that provide high spectral resolution surface albedo that can be used for high spectral resolution radiative transfer modeling or that can be easily averaged over the various wavelength ranges used in different radiative transfer models. Satellite products provide important information about spatial variability of albedo, but they have limited temporal and spectral sampling and must be corrected for atmospheric effects (Schaaf et al., 2002). Although detailed surface albedo measurements are often gathered for specific field experiments (e.g., Michalsky et al., 2003; Li et al., 2002; Liang et al., 2002) for closure studies to be most useful in identifying issues with the inputs, measurements, or models, calculations need to be run routinely under a wide range of atmospheric conditions.

The primary goal of this study is to develop and evaluate a routine long-term spectral albedo product for the ARM Southern Great Plains (SGP) site that can be used for radiative transfer calculations with a variety of models in combination with other measurements from the site. At the SGP central facility $(\mathrm{CF})$, spectral irradiance is measured by two sets of upward-looking 6-channel multi-filter rotating shadowband radiometers (MFRSRs) combined with downwardlooking multi-filter radiometers (MFRs) located on a $10 \mathrm{~m}$ tower and at the $25 \mathrm{~m}$ level on a $60 \mathrm{~m}$ tower. Since the MFR measurements only cover the spectral range from 415$940 \mathrm{~nm}$, prediction of the spectral albedo at longer wavelengths is challenging. We present a method for producing a high resolution spectral albedo product that consists of creating best estimate broadband and spectral channel albedos from MFRSR and MFR irradiance measurements, identifying the dominant observed surface type, and using libraries of high spectral resolution albedo for various surface types to extrapolate the 6-channel MFR albedo measurements from 820 to $50000 \mathrm{~cm}^{-1}(0.2$ to $12 \mu \mathrm{m})$ at $10 \mathrm{~cm}^{-1}$ resolution. The uncertainties in the extrapolated albedos are evaluated by comparison to high spectral resolution measurements taken during several field experiments at the site and by comparing integrated spectral albedos to measured broadband albedos.

\section{Data}

\subsection{Radiometer measurements}

The SGP site has several suites of radiometers, as indicated on the map in Fig. 1. At the CF radiometer area, there are two ground-based MFRSRs ( $\mathrm{mfrsrC} 1$ and $\mathrm{mfrsrE} 13$ ) and three sets of ground-based Eppley precision spectral pyranometers (PSPs) and pryheliometers that are part of the Solar and Infrared Radiation Station (SIRS) and Broadband Radiometer Station (BRS) networks. Additionally there are two $10 \mathrm{~m}$ towers (the SIRS tower in the upper left corner of the radiometer area and the Surface Meteorological Observing System (SMOS)), both of which have downward-looking PSPs. The SMOS tower also has a downward looking MFR. A second downward-looking MFR (along with a downwardlooking PSP) is located at the $25 \mathrm{~m}$ level of the $60 \mathrm{~m}$ tower, approximately $300 \mathrm{~m}$ from the CF radiometer area. (For simplicity, in the remainder of the paper, we will refer to this second tower and the instruments located on it as the $25 \mathrm{~m}$ tower.)

The MFRs measure shortwave global irradiance in six narrowband channels $(415,500,615,673,870$, and $940 \mathrm{~nm})$ and one broadband channel at $20 \mathrm{~s}$ intervals. The narrowband filters have a $10 \mathrm{~nm}$ full width at half maximum bandwidth and are periodically calibrated using lamp calibrations and Langley plots, except for the $940 \mathrm{~nm}$ channel which only uses lamp calibrations (Flynn and Hodges, 2005). The silicon broadband channel has a wavelength range of $300-1100 \mathrm{~nm}$. The MFRSRs measure total and diffuse downwelling spectral irradiance at the same channels as the MFRs. A rotating shadowband periodically blocks the solar disk for the diffuse measurement, and then the direct downwelling irradiance is derived by subtracting the diffuse irradiance from the total irradiance.

Along with the MFR and MFRSR measurements, we use measurements of shortwave broadband upwelling irradiance from downward-looking unshaded Eppley PSPs and downwelling broadband shortwave global, diffuse, and direct irradiance from Eppley pyranometers and pryheliometers. The Eppley thermopile instruments have a more uniform spectral response and broader wavelength range than the MFRSR broadband channels, and are therefore the preferred broadband measurement. We use broadband shortwave data from the sgpbeflux1longC1.c1 data stream, which performs quality control checks and inter-comparisons of the three groundbased broadband systems and the two PSPs on the $10 \mathrm{~m}$ towers to determine best estimate irradiances (Shi and Long, 2002). In the following, we will refer to the best estimate downwelling broadband shortwave global irradiance from the Eppley instruments as BEFlux, and the best estimate upwelling broadband shortwave irradiance from the Eppley PSPs on the $10 \mathrm{~m}$ towers as the $10 \mathrm{~m}$ PSP (although the value may in fact be an average of the measurements on the two $10 \mathrm{~m}$ towers). 


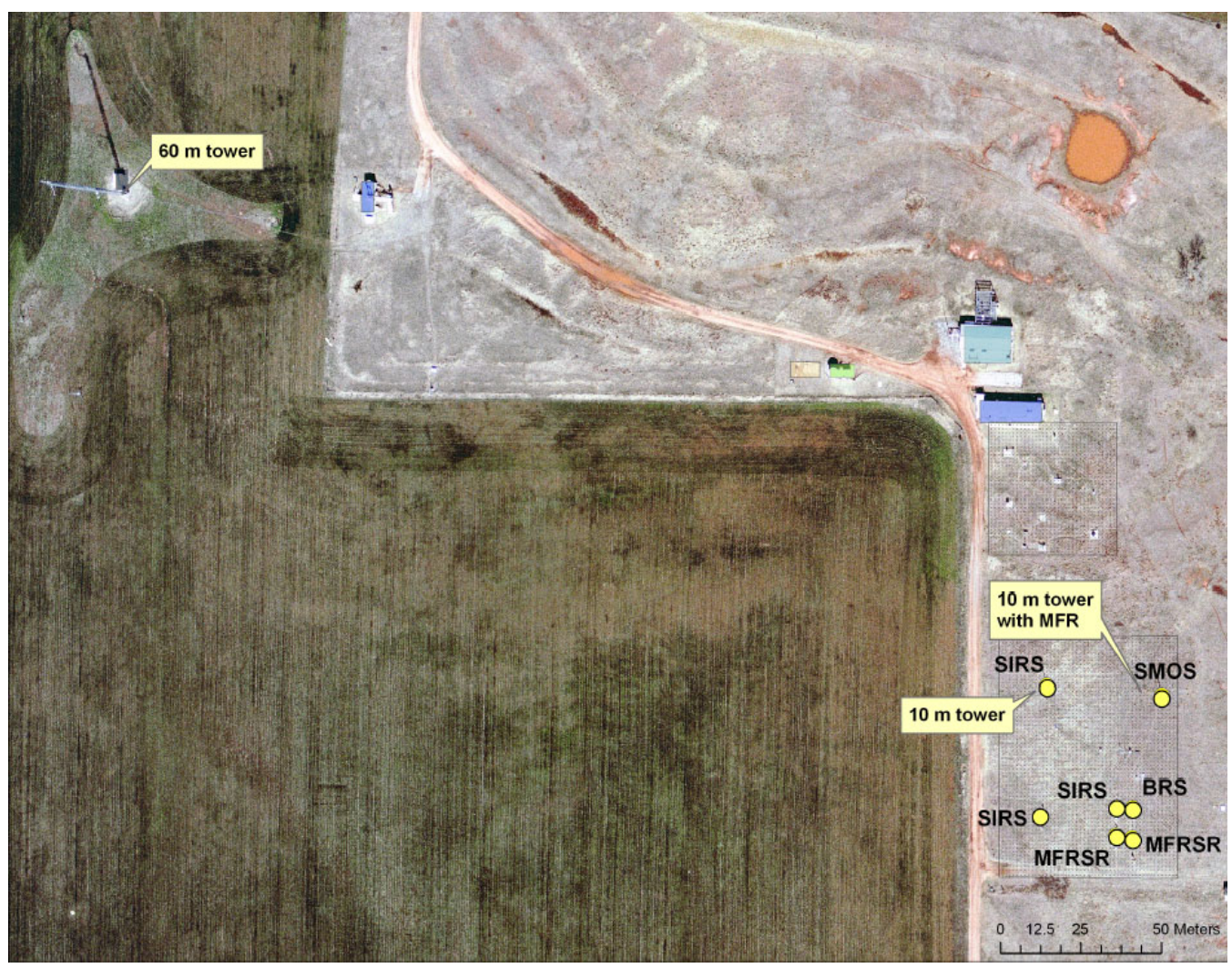

Fig. 1. Map of SGP central facility indicating the location of the radiometers used in this study. Photo courtesy of Aerial Oklahoma, Inc. Map annotations provided by Alice Cialella, Brookhaven National Laboratory.

The two MFRs measure upwelling spectral irradiance above different surface types: the $10 \mathrm{~m}$ MFR is located in an un-mowed pasture while the $25 \mathrm{~m}$ MFR is located in a cultivated field. Prior to the fall of 2004 the field under the $25 \mathrm{~m}$ MFR was planted with winter wheat, since then the field has been planted with various crops including corn, wheat, and soybeans. These two sites are representative of typical surfaces in the area surrounding the CF, although they do not cover the full range of variability of vegetation types. The spectral albedo of the surfaces under the two towers varies considerably over the year as the vegetation characteristics change or crops or planted and harvested.

\subsection{Best estimate MFR and broadband albedos}

To produce near continuous best estimate albedos in the six MFR spectral channels, we determine the best estimate of the downwelling and upwelling irradiance values measured by the MFRSRs and MFRs, fill in missing irradiance values where possible, calculate the albedo for periods for which the irradiance data existed, and then fill in the remaining gaps in the narrowband spectral albedo where possible. A brief description of the process used in each of these steps is presented below; further details are available in McFarlane et al. (2011).

\subsubsection{Downwelling irradiance}

For each day, the MFR and MFRSR $20 \mathrm{~s}$ samples are first averaged up to $60 \mathrm{~s}$ to match the time resolution of the BEFlux data. The MFRSR broadband data are then calibrated by calculating a linear scaling factor in comparison to the BEFlux data for each instrument. Simple ratio tests between the mfrsrC1, mfrsrE13, and BEFlux datasets are used to determine whether to use $\mathrm{mfrsrC} 1, \mathrm{mfrsrE} 13$ or an average of the two measurements as the preferred MFRSR broadband measurement. Cases where both mfrsrC1 and mfrsrE13 are missing or neither is within $10 \%$ of the BEFlux value are labeled missing. The MFRSR broadband measurements are used primarily to quality control and fill in missing values of the narrowband values, as described below.

Only samples for which the downwelling MFRSR broadband measurements are good are considered in the narrowband analysis. Samples for which BEFlux $<200 \mathrm{Wm}^{-2}$ cannot be evaluated because of uncertainty in the ratios at these low irradiance values, so they are kept but flagged as indeterminate. Ratios between the mfrsrC1 and mfrsrE13 measurements are calculated for each narrowband channel. For ratios between 0.90 and 1.10, either the two measurements are averaged (if both broadband measurements were good) or the value from the instrument used for the broadband 
measurement is chosen. For smaller or larger ratios, the sample is labeled as bad.

To estimate downwelling broadband values for missing data, the average value of the ratio of the downwelling MFRSR broadband value to the BEFlux value is calculated for good samples occurring immediately before and/or after the missing period. For each sample during the missing period, the BEFlux value is multiplied by the calculated ratio. Samples for which BEFlux is missing or less than $200 \mathrm{Wm}^{-2}$ are not corrected. Only data gaps less than $30 \mathrm{~min}$ long are filled, and there must be at least as many good samples immediately preceding or following the gap as there are missing samples. Once the broadband values are corrected, estimates are made for missing narrowband values using the same procedure but using ratios of the given narrowband value to the broadband value. At this time, no dependence on solar zenith angle or cloud cover is considered when filling in missing narrowband values, although the ratio of narrowband to broadband irradiance does depend somewhat on these factors (Liang, 2000).

\subsubsection{Upwelling irradiance}

For the upwelling irradiance values, suspect irradiance data are removed through a variety of techniques including ratio tests between the available measurements, the application of minimum, maximum, and standard deviation limits identified through seasonal and diurnal analysis, and filtering for suspect conditions such as small irradiance values and large solar zenith angles. Large standard deviations often occur at low sun angles, so all samples with cosine of solar zenith angle $\left(\mu_{0}\right)$ less than 0.15 are removed from the analysis. As described for the downwelling irradiance values, missing and bad upwelling irradiance values are estimated using expected ratios between the irradiances needed and a known good reference value. For the broadband $10 \mathrm{~m}$ and $25 \mathrm{~m}$ MFR upwelling values, the reference value is the corresponding $10 \mathrm{~m}$ or $25 \mathrm{~m}$ PSP value. For the narrowband MFR upwelling irradiances, the reference value is the corresponding upwelling broadband value (which has already been quality controlled).

\subsubsection{Albedo calculations}

MFR broadband and narrowband surface albedo values are calculated for both the $10 \mathrm{~m}$ and $25 \mathrm{~m}$ towers by dividing the best estimate of the upwelling irradiance from the MFR for the appropriate tower by the best estimate of the MFRSR downwelling irradiance for the central facility. Due to uncertainty in calculated albedos when downwelling and upwelling irradiances are small, broadband albedos are not calculated for periods where the BEFlux is less than $50 \mathrm{Wm}^{-2}$. Narrowband albedos are calculated for all samples for which both the narrowband data is considered good and for which a broadband albedo could be calculated. Albedo values for which one of the input irradiance values was estimated as described above are flagged and labeled "irradiance estimated" in the analysis presented in Sect. 4.

For periods with missing or bad albedo values, estimates of the broadband and narrowband albedo are made, however the albedo estimation method depends on whether the sky conditions are classified as diffuse (direct irradiance $<15 \%$ of total irradiance) or direct. For diffuse conditions, there is little dependence of surface albedo on solar zenith angle, and so the albedo value near solar noon can be used to represent the entire day. The near noon albedo for both the $10 \mathrm{~m}$ and $25 \mathrm{~m}$ towers is calculated for all days for which there are a sufficient number of samples under diffuse conditions during the one hour periods before or after solar noon. For days not meeting that condition, the near noon albedo is estimated by interpolating from surrounding days.

For direct conditions there is a strong dependence of albedo on solar zenith angle, which must be taken into account in estimating the albedo over the course of the day (Henderson-Sellers and Wilson, 1983). For days with sufficient number of samples under direct albedo conditions, the slope and offset of the best fit line relating direct albedo to $\mu_{0}$ are calculated and used to estimate the missing albedos (McFarlane et al., 2011). For days without enough direct albedo samples, the values of the albedo slope and offset are interpolated from surrounding days.

Broadband and narrowband MFR albedos are calculated using the same methodology, but with different near noon albedo values and different fit coefficients for direct conditions. Albedo values estimated using the procedures described above are flagged and are labeled as "albedo estimated" in later analysis. The final dataset contains a near continuous set of measured or estimated broadband and narrowband albedo values for all samples where $\mu_{0}>0.15$.

PSP broadband albedo values are calculated using the $10 \mathrm{~m}$ and $25 \mathrm{~m}$ PSP upwelling irradiance values and the downwelling irradiance from the BEFlux dataset. As in the other datastreams, samples with BEFlux $<200 \mathrm{Wm}^{-2}$ are flagged as indeterminate and albedo calculations are not made for samples with $\mu_{0}<0.15$. As the PSP broadband albedo is mainly used to evaluate the spectral albedo estimation, no estimates are made to correct for missing or bad PSP albedo values.

The surface albedo calculated as a ratio of measured upwelling to downwelling irradiances can be more properly referred to as the "apparent" surface albedo, since it depends on atmospheric conditions that can affect the relative distribution of downwelling irradiance with wavelength, such as water vapor, aerosol, and clouds (Liang et al., 1999). The spectral distribution of the incoming irradiance weights the "true" or "inherent" monochromatic surface albedo, which depends solely on the characteristics of the surface, to give you the apparent albedo. In this study, we will use the term surface albedo to refer to the measured apparent albedo. 


\subsection{Spectroradiometer measurements}

During several intensive observational periods (IOPs) conducted 14-19 August 2002, 20-26 October 2004 and 812 February 2004, spectral surface albedo measurements were taken over a wide variety of surface conditions at various locations around the SGP central facility (Trishchenko et al., 2003). During the August 2002 IOP, albedo was measured with a GER3700 spectroradiometer $(320-2500 \mathrm{~nm})$ and during the 2004 IOPs, albedo was measured with an Analytical Spectral Devices (ASD) FieldSpec Pro spectroradiometer (350-2500 $\mathrm{nm}$ ). The ASD had spectral sampling resolution of $1.5 \mathrm{~nm}$ over the full range, although there were often sampling gaps between $\sim 1300$ to $1450 \mathrm{~nm}$, between 1800 to $1950 \mathrm{~nm}$, and beyond $2000 \mathrm{~nm}$. The location of the gaps shifted somewhat between measurements. The GER had spectral sampling resolution of $1.5 \mathrm{~nm}$ over the range $300-1050 \mathrm{~nm}, 6.2 \mathrm{~nm}$ over the range $1050-1900 \mathrm{~nm}$, and $9.5 \mathrm{~nm}$ over the range $1900-2500 \mathrm{~nm}$ and could take measurements with $3^{\circ}$ or $9^{\circ}$ field of view or $180^{\circ}$ if a diffuser was used. The GER measurements often had sampling gaps between 1900-2000 nm. In general, the measured spectral albedos tended to be noisier for wavelengths longer than $1600 \mathrm{~nm}$.

For each measurement, the time of measurement, surface conditions, cloud cover, and photographs of the measurement sites were documented in field reports (Trishchenko et al., 2003, 2004a, b). Measurements were taken below the $10 \mathrm{~m}$ and $25 \mathrm{~m}$ MFRs and at other sites around the CF. Surface conditions included bare soil, various stages in the growth cycle of grass, wheat and soybeans, corn/wheat stubble, and snow. The snow occurred just prior to the start of the October 2004 IOP and melted during the first two days of the IOP.

During this IOP there were several occasions where the spectral albedo measurements were unexpectedly high and noisy at wavelengths beyond $1000 \mathrm{~nm}$. Examination of the photographs and measurement logs indicated that during these observations, residual ice or snow on the ground may have affected the measured albedo. These cases were not used in the following analysis. The high spectral resolution measurements from the IOPs are used in Sect. 4.1 to evaluate the method of extrapolating the MFR narrowband albedos to a broader wavelength range and higher spectral resolution.

\section{Identification of surface type}

The spectral albedo of a land surface is a function of the existence, extent, and type of vegetation that covers the area; if two different areas have the same surface characteristics then their spectral albedos will also be similar (Liang et al., 1999). We assume that if a set of surface types that characterize a site and result in unique spectral albedo signatures can be identified, they can also be used to predict the spectral albedo. Estimating spectral albedo for all times at the SGP

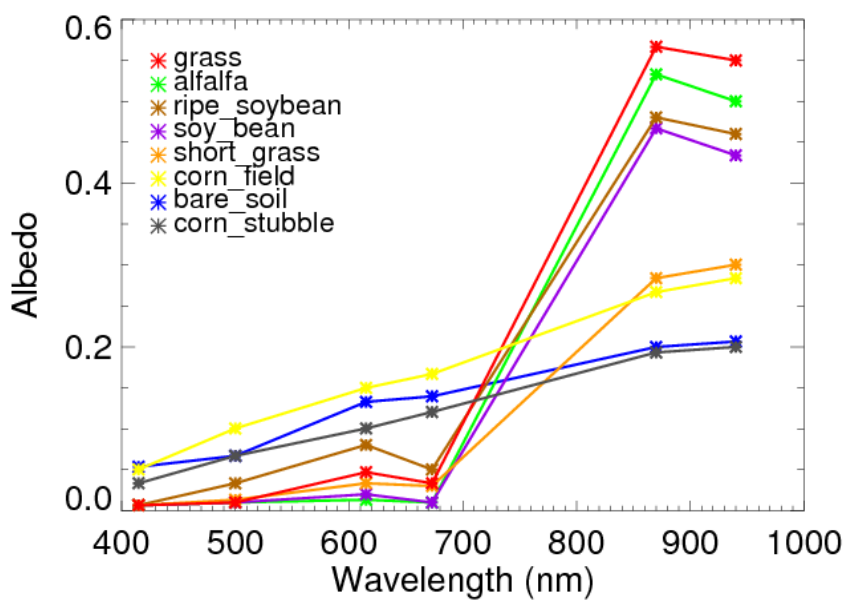

Fig. 2. Spectral albedo values at the MFR wavelengths for different surface types, adapted from figures in Liang et al. (2002).

central facility requires that a set of surface types be identified using only the albedos corresponding to the six MFR operating wavelengths. Figure 2 shows the values of the narrowband albedos at the six MFR wavelengths for the spectral measurements presented in Liang et al. (2002). The MFR operating wavelengths do not contain enough information to distinguish between particular types of lush green vegetation (i.e. soybean and wheat in Fig. 2) but there are distinct differences at the MFR wavelengths between lush vegetated surfaces (soybean, etc.), partially vegetated surfaces in which green vegetation exists, but is not lush enough to completely shield the soil (grass, short grass) and brown surfaces (bare soil, corn stubble).

To further assess the utility of the MFR wavelengths for distinguishing between vegetated and non-vegetated surfaces, we examined a dataset consisting of visual assessments made by site personnel during 2001 (the sgpsurflogC1.c1 data stream; hereafter referred to as surflog) and images from the Total-Sky Imager (TSI). The TSI, which is located near the $10 \mathrm{~m}$ tower has a hemispheric mirror that reflects the sky to observe clouds. Around the edges of the TSI image, the surface conditions near the $10 \mathrm{~m}$ tower can be seen (e.g., Fig. 3 top panels). The surflog visual assessments were performed roughly twice a month at the central facility, limiting the dataset to approximately 25 days spread across 2001.

For each case for which a surflog assessment and a TSI image were available, we examined the values of the MFR narrowband albedos for a period from one hour before to one hour after solar noon. Several examples of the MFR observations and corresponding TSI images are presented in Fig. 3. In the first case, 17 May 2001, the surflog report states "lush green" at the $10 \mathrm{~m}$ tower and "green ground" at the $25 \mathrm{~m}$ tower, and the TSI image shows green vegetation at the $10 \mathrm{~m}$ tower. The MFR narrowband albedos at the two towers show 

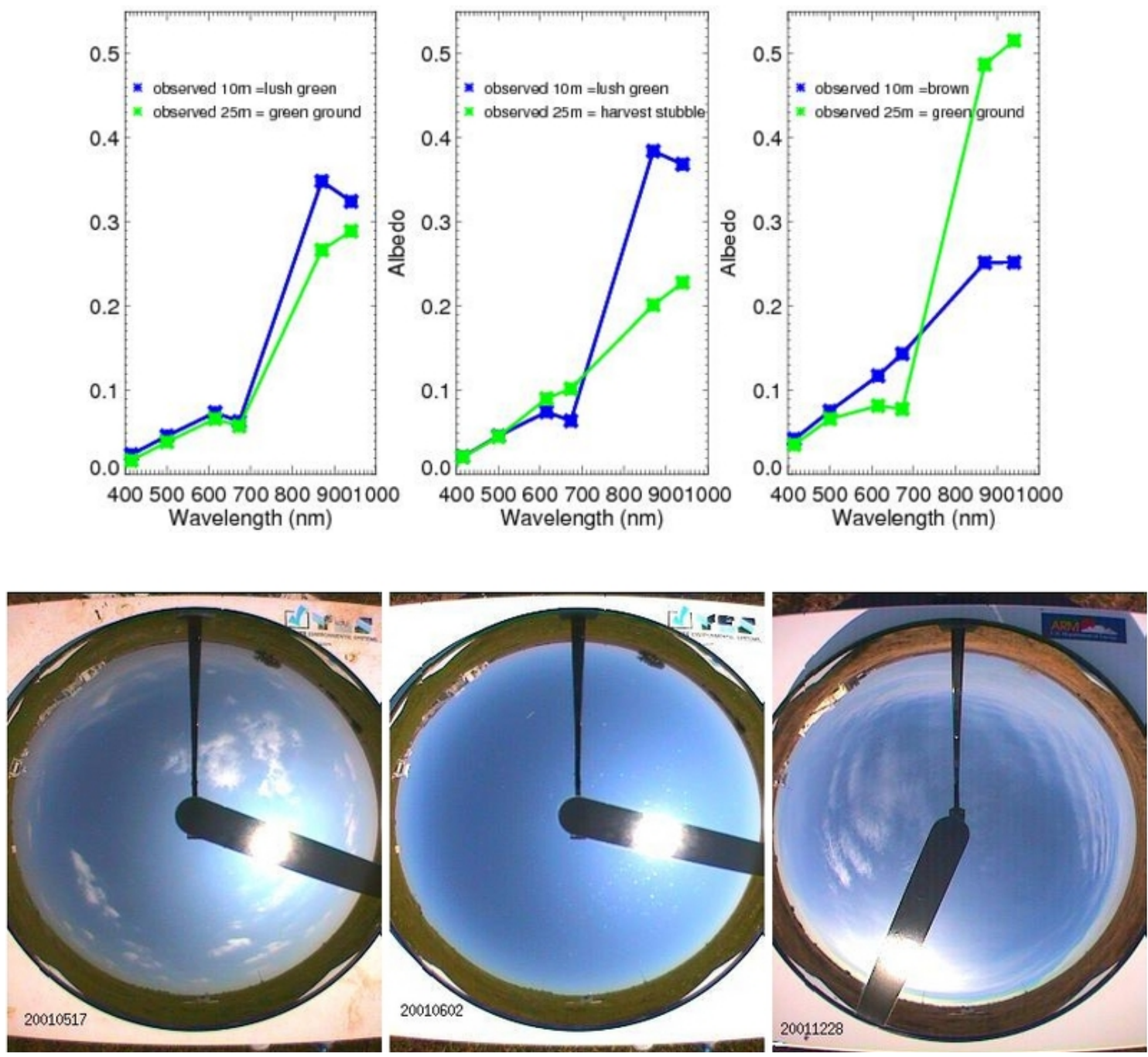

Fig. 3. Examples of (top) MFR measurements and (bottom) TSI images for several different surface types as indicated by observers in the surflog datastream.

very similar characteristics, representative of green vegetation, with low values in the visible, a dip in albedo between 615 and $673 \mathrm{~nm}$, and high values in the near-IR. For the second case, 31 May 2001 the surflog report indicates that the winter wheat under the $25 \mathrm{~m}$ tower had been recently harvested and the MFR albedo shows characteristics of bare soil or dead vegetation, with a fairly linear relationship between the visible and near-IR albedos. The $10 \mathrm{~m}$ tower is still "lush green" as reported in the surflog and seen in the TSI images (from 2 June 2001) and the MFR albedos. Finally, in the last case, on 28 December 2001, winter wheat under the $25 \mathrm{~m}$ tower is growing as indicated by the "green ground" report from the surflog and the MFR albedos. However, at the $10 \mathrm{~m}$ tower, the grass is dry and brown as evidenced by the TSI image and the surflog report: "brown", and the MFR albedos for the $10 \mathrm{~m}$ tower show the typical characteristics of bare soil or dead vegetation. These examples show how three distinct surface types can be identified from the MFR wavelengths. In the following analysis, we will refer to these three types as vegetated, partially vegetated, and non-vegetated. The non-vegetated cases may consist of soil or of dying or dead vegetation.

Examination of the MFR measurements over the course of several years determined that snow covered ground could also be identified by its high visible albedo and the ratio of visible to near-IR albedo. Albedo thresholds for identifying snow (Table 1) were determined based on libraries of spectral albedo values (Bowker et al., 1985; Baldridge et al., 1999). Snow albedo varies significantly based on the age, thickness, and grain size of the snow (Gardener and Sharp, 2010) and whether the underlying surface can be seen beneath the snow. Since there were few validation cases for snow, if the albedo test indicates a snow covered surface, then a spectral extrapolation is not performed at this time. Analysis of the ASD 
Table 1. Albedo and NDVI thresholds for determining surface type.

\begin{tabular}{ll}
\hline Surface type & Surface type criteria \\
\hline Snow & $\alpha(415)>0.17$ AND $\alpha(615) / \alpha(870)>0.65$ \\
$100 \%$ vegetation & NDVI $\geq 0.58$ \\
Partial vegetation & $0.25<\mathrm{NDVI}<0.58$ \\
$0 \%$ vegetation & NDVI $\leq 0.25$ \\
\hline
\end{tabular}

data during conditions where scattered snow and ice existed on a surface indicate that the six MFR narrowband measurements may not be sufficient to identify snow as it starts melting and the underlying surface begins to show. Thus, in use of the MFR data operationally, the extrapolated albedos for several days after an identified snow case should be treated with caution.

To remove the influence of solar zenith angle, we estimate surface type once per day using the average albedo for the two hour period around solar noon. If the surface is not snow-covered, we determine whether it is vegetated, partially vegetated, or non-vegetated. We examined several methods for quantitatively separating vegetated, partially vegetated, and non-vegetated surfaces, and determined that a version of the Normalized Difference Vegetation Index (NDVI) was the most robust indicator of vegetated surfaces. The NDVI is an established indicator used by the remote sensing community to measure the amount of green vegetation in a surface (Myneni et al., 1995) and is based on the fact that green vegetation preferentially absorbs radiation at visible spectral wavelengths and reflects radiation at near-infrared wavelengths. It is calculated as the ratio of the difference between the nearinfrared reflectance $\left(\alpha_{\mathrm{NIR}}\right)$ and the red reflectance $\left(\alpha_{\mathrm{RED}}\right)$ to the sum of these same values:

$\mathrm{NDVI}=\left(\alpha_{\mathrm{NIR}}-\alpha_{\mathrm{RED}}\right) /\left(\alpha_{\mathrm{NIR}}+\alpha_{\mathrm{RED}}\right)$

For the MFR instruments, we use the $870 \mathrm{~nm}$ (channel 5) measurement as the $\alpha_{\mathrm{NIR}}$ value and the $673 \mathrm{~nm}$ (channel 4) measurement as the $\alpha_{\text {RED }}$ value. In general, dense vegetation has a high NDVI, bare soil has low positive values, and water has negative values due to strong NIR absorption (Myneni et al., 1995). Although NDVI is a useful tool for studying vegetation characteristics, the thresholds for determining whether a surface is vegetated or not depend on the details of the surface under consideration, the field of view of the instrument, and the wavelength channels used. Previous studies have shown that NDVI sensitivity decreases at high values, and the maximum NDVI usually occurs near $0.5-0.8$ for dense vegetation, but can vary with vegetation type (Carlson and Ripley, 1997). Similarly, bare soil values can vary considerably with the soil type.

To define thresholds for non-vegetated and $100 \%$ vegetated surfaces, we visually inspected the MFR narrowband albedos from several years and identified days that could be considered vegetated and non-vegetated. Based on the NDVI values in these cases, as well as examination of the differences between measured and estimated albedos (discussed further in next section), we obtained the threshold values given in Table 1. We also examined the use of other MFRSR channels, but found that the $673 \mathrm{~nm}$ and $870 \mathrm{~nm}$ channels gave the best separation.

For partial vegetation cases, we assume that the albedo can be estimated as a weighted average between the spectral albedos of fully vegetated and non-vegetated surfaces,

$\alpha_{p}=f \alpha_{100}+(1-f) \alpha_{0}$,

where $f$ is the vegetation fraction and $\alpha_{p}, \alpha_{100}$, and $\alpha_{0}$ are the albedos of the partially vegetated surface, fully vegetated surface, and non-vegetated surface, respectively (Jiang et al., 2006). Several studies (Wittich and Hansing, 1995; Kustas et al., 1993) have indicated a linear relationship between vegetation fraction and a scaled NDVI value,

$f=\frac{\left(\mathrm{NDVI}-\mathrm{NDVI}_{0}\right)}{\left(\mathrm{NDVI}_{100}-\mathrm{NDVI}_{0}\right)}$,

where $\mathrm{NDVI}_{100}$ and $\mathrm{NDVI}_{0}$ are the NDVI threshold values from Table 1 for the fully and non-vegetated surfaces, respectively. Other studies found that vegetation fraction was related to the square of the scaled NDVI value.

Direct evaluation of the daily surface type and fractional vegetation are not possible for our dataset as there are no verification datasets. We perform an indirect evaluation of the surface type and percent vegetation estimates by comparing our estimates of extrapolated spectral albedo to field measurements of spectral albedo for different surfaces. Results of these comparisons are shown in the next section. Examination of the linear and square relationships between vegetation fraction and scaled NDVI found that the linear relationship gave smaller standard deviation between estimated and actual values (not shown) so the linear relationship was used in the remainder of the study.

\subsection{Time series of daily surface type}

We examine the time series of estimated daily surface type for each site (Fig. 4) to determine if they make physical sense. Under the $10 \mathrm{~m}$ tower, the seasonal behavior is fairly consistent from year to year (Fig. 4a). The initial spring growth of the grass in the un-mown pasture under the $10 \mathrm{~m}$ tower, and the rapid increase from $0 \%$ to $100 \%$ vegetation can be clearly seen (Fig. 4a) and seem to occur near the same time each year. Most summers, the percent vegetation decreases from $100 \%$ to approximately $20 \%$ as the grass dies in the summer heat. The percent vegetation increases again in the fall, before falling off to $0 \%$ in the winter. The timing and magnitude of the summer decrease and fall recovery vary from year to year, likely due to changes in precipitation. Overall, the seasonal cycle of the percent vegetation at the $10 \mathrm{~m}$ tower is reasonable and gives confidence in the general 

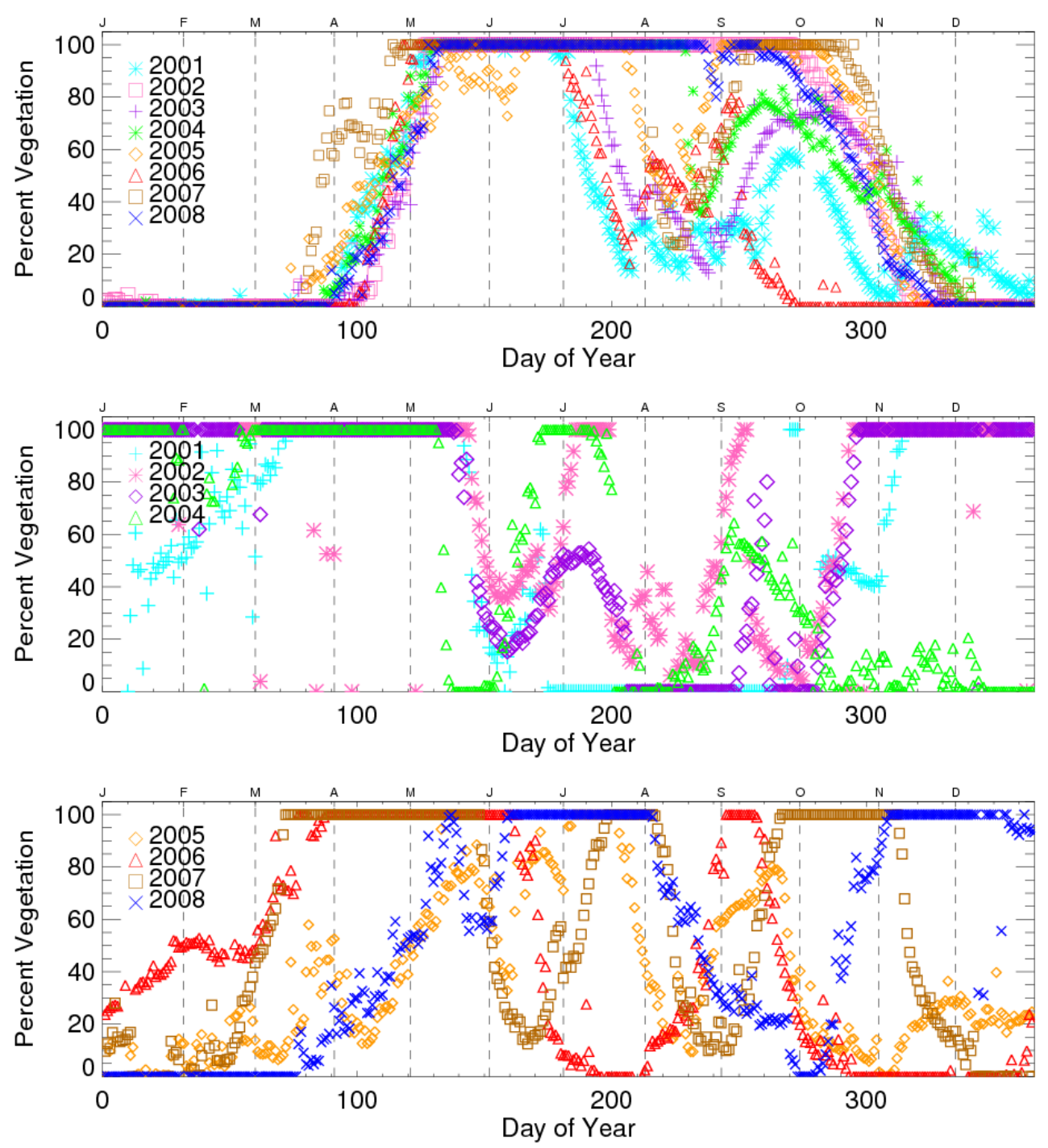

Fig. 4. Time series of daily percent vegetation derived from MFR measurements for (top) 2001-2008 at $10 \mathrm{~m}$ tower, (middle) 2001-2004 at $25 \mathrm{~m}$ tower, and (bottom) 2005-2008 at $25 \mathrm{~m}$ tower. Days with missing data and days classifed as snow are not included in the plots.

methodology, although the actual values of percent vegetation cannot be directly evaluated.

The annual cycle at the $25 \mathrm{~m}$ tower is more complicated because it is a managed field and there was a change in crops during the analysis period. Information on the cultivation practices of the managed field comes from the SGP site operations personnel (Pat Dowell, personal communication, 2011). From 2001 through the spring of 2004, the field under the $25 \mathrm{~m}$ MFR was planted in winter wheat, which is typically planted in September/October and harvested in June (USDA). Also during this period, the field was typically tilled two or three times during the summer months after the wheat harvest. The seasonal cycle of the percent vegetation (Fig. 4b), illustrates the impact of these activities. The site shows $100 \%$ vegetation in the colder months (November to May) due to the growth of winter wheat. A minimum in veg- etation occurs around June in most years due to the harvest. Some years show an increase in vegetation again immediately after the presumed harvest, which is likely due to weeds growing in the fallow fields (as seen in images in the field reports). A second dip in vegetation percentage in August and greening up in September in most years is due to the periodic tilling and re-growth of weeds, although it may also be impacted by variations in precipitation from year to year. A gradual greening up of the $25 \mathrm{~m}$ tower site begins again in fall, when the winter wheat is planted (although this did not happen in the fall of 2004 due to the change in crops).

During the 2005-2008 period, the farming practices significantly changed. Instead of planting winter wheat each fall, harvesting in the spring, and periodic tilling in the summer, the farmer changed to a no-till method of farming and also planted a wider variety of crops. The annual cycle of 
percent vegetation under the $25 \mathrm{~m}$ MFR is quite variable during 2005-2008 (Fig. 4c) due to the variety of crops planted (corn, wheat, and soybeans), which are planted and harvested at different times of the year. In 2005, corn was planted in the spring and harvested in August, then winter wheat was planted into the corn stubble in the fall. In 2006, the wheat was harvested in late June, soybeans were planted roughly a week later and harvested in November, and wheat was planted again in November. In 2007, which had an extremely wet summer, part of the wheat crop was harvested in July, but the remainder was not harvested until early September, and the field was left fallow the remainder of the year. In 2008, corn was planted in late April and harvested in late September and wheat was planted a week later.

In general the surface type retrieval is in agreement with the major activities noted in the field notes. Quite often, the percent vegetation begins to decline from $100 \%$ before the noted date of harvest. This may be due to the fact that broadleafed herbicides are often sprayed in the fields a few weeks before harvest or due to the tendency for some crops to turn yellow as they are ready to be harvested.

\section{Estimation of high spectral resolution surface albedo}

Given the limited information available at the MFR wavelengths, we have to use other information about the typical spectral structure of albedo to extrapolate to high spectral resolution and to wavelengths outside of the MFR measurements. Our goal is to produce an estimate of the albedo at high spectral resolution that is representative of the given surface type, that matches the MFR albedo values at the available wavelengths, and that reasonably reproduces the broadband albedo.

Several libraries of observed high spectral resolution albedos of various surface types (Bowker, 1985; ASTER, 1999) were used to develop a spectral extrapolation method. Peaks and troughs in the observed spectral albedo values and differences between vegetated and non-vegetated surfaces were used to identify distinct spectral regions. Separately for vegetated and non-vegetated surfaces, piecewise continuous functions were developed to estimate the albedo across each spectral region given the input MFR albedos and the characteristics of the spectral libraries. Seven soil types, ranging from very dark grayish brown loam to dark reddish brown fine sandy loam, and over 20 vegetation types including wheat, various grasses, and other crops were composited to derive these functions. Since the MFR measurements only cover the spectral range from 415 to $940 \mathrm{~nm}$, the extrapolation beyond these wavelengths is expected to be more uncertain.

The surface type and percent vegetation estimate is made once per day, using an average of the MFR data for a two hour period around solar noon. Then, for each MFR sample time the six narrowband albedos are used to scale the function for the appropriate surface type. The functions pro- duce albedo from 820 to $50000 \mathrm{~cm}^{-1}(0.2$ to $12.0 \mu \mathrm{m})$ at $10 \mathrm{~cm}^{-1}$ resolution. We provide values down to $820 \mathrm{~cm}^{-1}$ $(12.0 \mu \mathrm{m})$ for completeness as different solar radiative transfer codes have different longwave cut-offs; values at smaller wavenumbers (longer wavelength) have large uncertainties and are not meant to be used for longwave emissivity. For partially vegetated surfaces, the spectral albedos for vegetated and non-vegetated surfaces are calculated separately and then weighted appropriately using Eq. (2).

For vegetation, the spectrum is broken into 21 spectral regions. As discussed in Bowker et al. (1985), different factors control reflectance in the different spectral regions. Below $700 \mathrm{~nm}$, the reflectance is controlled primarily by absorption by leaf pigments (such as chlorophyll). A sharp increase in albedo occurs around $700 \mathrm{~nm}$, and between $700-1300 \mathrm{~nm}$ reflectance is dominated by leaf cellular structure. Beyond $1300 \mathrm{~nm}$, reflectance is primarily controlled by leaf water content. Troughs in albedo due to water absorption bands occur near 1400 and $1950 \mathrm{~nm}$ and weaker water absorption features are seen at 980 and $1240 \mathrm{~nm}$. The strength of these water absorption features in observed vegetative surfaces depends on the leaf water content and can vary both by plant type and by environmental conditions.

For non-vegetated surfaces, 24 spectral regions are used in the estimation. In this study, the non-vegetated surfaces are modeled like the "Type 2" soil surfaces discussed in Bowker et al. (1985), which have a roughly linear slope to $600 \mathrm{~nm}$, and then a slightly convex shape from the visible region to $1400 \mathrm{~nm}$. The water absorption bands at 1400 and $1950 \mathrm{~nm}$ are sharper than in the vegetated surfaces, however the strength of these absorption features depends on soil moisture. The non-vegetated surfaces are also assumed to have an absorption band at $2200 \mathrm{~nm}$. This is associated with $\mathrm{OH}$ absorption and is often seen in soils (particularly clay soil) but may not be present in dead (yellow) vegetation (Bowker et al., 1985).

\subsection{Evaluation of estimated spectral albedo}

The ASD and GER high resolution spectral measurements were used to evaluate the albedo estimation method. For each measurement, the values closest to the MFR wavelengths were extracted and input to the surface type and albedo extrapolation algorithms, and then the estimated albedo was compared to the measurements. The measurements and field reports were used to identify cases of non-vegetated surfaces (bare soil, dry wheat, wheat stubble, and some grass/pasture cases in February), $100 \%$ green vegetated surfaces (grass, soybeans, milo, wheat, and alfalfa), and partially vegetated surfaces (grass, wheat, corn stubble) for evaluation of the methodology.

Table 2 shows the number of cases for each IOP period and the number of measurements of each surface type. In some cases, multiple measurements of the same surface may have been taken with different fields of view of the radiometer 
Table 2. Number of cases of each surface type (as identified from current methodology) measured with spectroradiometer for each IOP period.

\begin{tabular}{lcccc}
\hline Date of IOP & Total \# Cases & $\begin{array}{c}\text { \# Cases with } \\
\text { 0\% vegetation }\end{array}$ & $\begin{array}{c}\text { \# Cases with } \\
\text { partial vegetation }\end{array}$ & $\begin{array}{c}\text { \# Cases with } \\
\text { 100 \% vegetation }\end{array}$ \\
\hline August 2002 & 29 & 11 & 6 & 12 \\
February 2004 & 28 & 12 & 6 & 10 \\
October 2004 & 41 & 4 & 33 & 4 \\
\hline
\end{tabular}

$\left(3^{\circ}, 10^{\circ}\right.$ or $\left.180^{\circ}\right)$ or on consecutive days. Each of these is treated as a separate measurement.

Some examples of measured and extrapolated spectral albedos are presented for each of the three surface types in Fig. 5 and are discussed below. The panels in the left-hand column are examples of cases where the surface type (including percent vegetation) and albedo extrapolation methodology appeared to work well, whereas the panels in the righthand column show examples of cases where either the percent vegetation estimation was incorrect or the spectral extrapolation was not a good match to the measurements.

\subsubsection{Non-vegetated surfaces}

Two cases of bare, plowed soil near the SGP central facility are examined. The first (Fig. 5a) is a field near the $25 \mathrm{~m}$ tower observed on 24 October 2004 under clear skies. In this case, the general shape of the spectral curve and the magnitude of the albedo are well-matched. However, there is a suggestion that the extrapolated albedo over-estimates the sharpness of the water absorption features at 1400 and $1950 \mathrm{~nm}$ relative to the measured albedo. In the second bare soil case (Fig. 5b), observed in the central facility area on 14 August 2002, the shape of the curve is again well matched up to $1900 \mathrm{~nm}$, and the extrapolation captures the magnitude of the albedo between 400 and $1300 \mathrm{~nm}$. Beyond $1300 \mathrm{~nm}$, the extrapolation overestimates the magnitude of the albedo. The difference in the magnitude of the albedo beyond $1300 \mathrm{~nm}$ in the estimate and observation may be due to the effects of soil moisture; wet soil has lower reflectance in the visible and nearIR (Lobell and Asner, 2002). Examination of the surface meteorological data at the SGP shows precipitation $>15 \mathrm{~mm}$ on both 12 and 13 August 2002 while less than $0.5 \mathrm{~mm}$ is recorded in the several days preceding the 24 October 2004 case.

To assess the spectral extrapolation methodology across various spectral regions, we also look at the statistics of the differences between the measured and extrapolated albedos in each of the spectral regions used in the algorithm. Figure 6 shows the average measured albedo and a box-whisker diagram of the albedo differences (measured-estimated) in each spectral region up to $2500 \mathrm{~nm}$ based on all 27 of the non-vegetated cases. In the box-whisker diagram, + marks the mean difference in the spectral bin, $x$ marks the median difference, the boxes give the 25 th and 75 th percentile val- ues, and the whiskers give the minimum/maximum values. In general, the means and medians are quite close and not distinguishable from each other in the plots. Standard deviations in each spectral region are also calculated, although not shown. For these comparisons, the spectral albedo for each case is estimated at the same wavelength resolution as the measured albedo, so multiple residuals are included within a given spectral region for each IOP surface measurement.

Generally, the estimated albedos for the non-vegetated cases have small errors (mean error $<7 \%$ ) and variability (standard deviation $<8 \%$ ) in spectral regions less than $1350 \mathrm{~nm}$. Mean errors are still less than $7 \%$ in the 1350 to $1920 \mathrm{~nm}$ region, but the standard deviation increases to $11-$ $30 \%$. For spectral regions beyond $1920 \mathrm{~nm}$, the mean errors are significant $(>16 \%)$ and the estimated albedo tends to overestimate the observed value. One reason for the large variability and mean error at the longer wavelengths is that the strength and locations of the estimated absorption features are not always a good match to the observations. In particular, the $\mathrm{OH}$ absorption band at $2200 \mathrm{~nm}$, which is one of the boundaries of the estimated spectral regions, is not really seen in the observations and the observations have a more curved shape in the 2200-2600 region than the estimated albedos (e.g., Fig. 5b). In future work, the estimated albedo methodology might be adapted to include information on soil moisture, which is available from the SGP central facility site beginning in December, 2002.

\subsubsection{Vegetated surfaces}

For the $100 \%$ vegetation cases, we again look at two specific observations near the central facility as examples of the algorithm's behavior. The first case (Fig. 5c), a wheat field observed on 10 February 2004 under clear sky conditions, shows a good match between the estimated albedo and the measurements in both the shape and magnitude of the albedo. The only spectral region that is not well matched is the 1900-2200 $\mathrm{nm}$ region, where the observed albedo has a slightly steeper slope than the estimated albedo. The second case (Fig. 5d), a different wheat field near the central facility, observed the previous day under conditions of $0-15 \%$ cirrus cloud cover, matches the observations well up to $940 \mathrm{~nm}$, but then overestimates the magnitude of the albedo, although the shape of the spectral albedo is still well matched. 

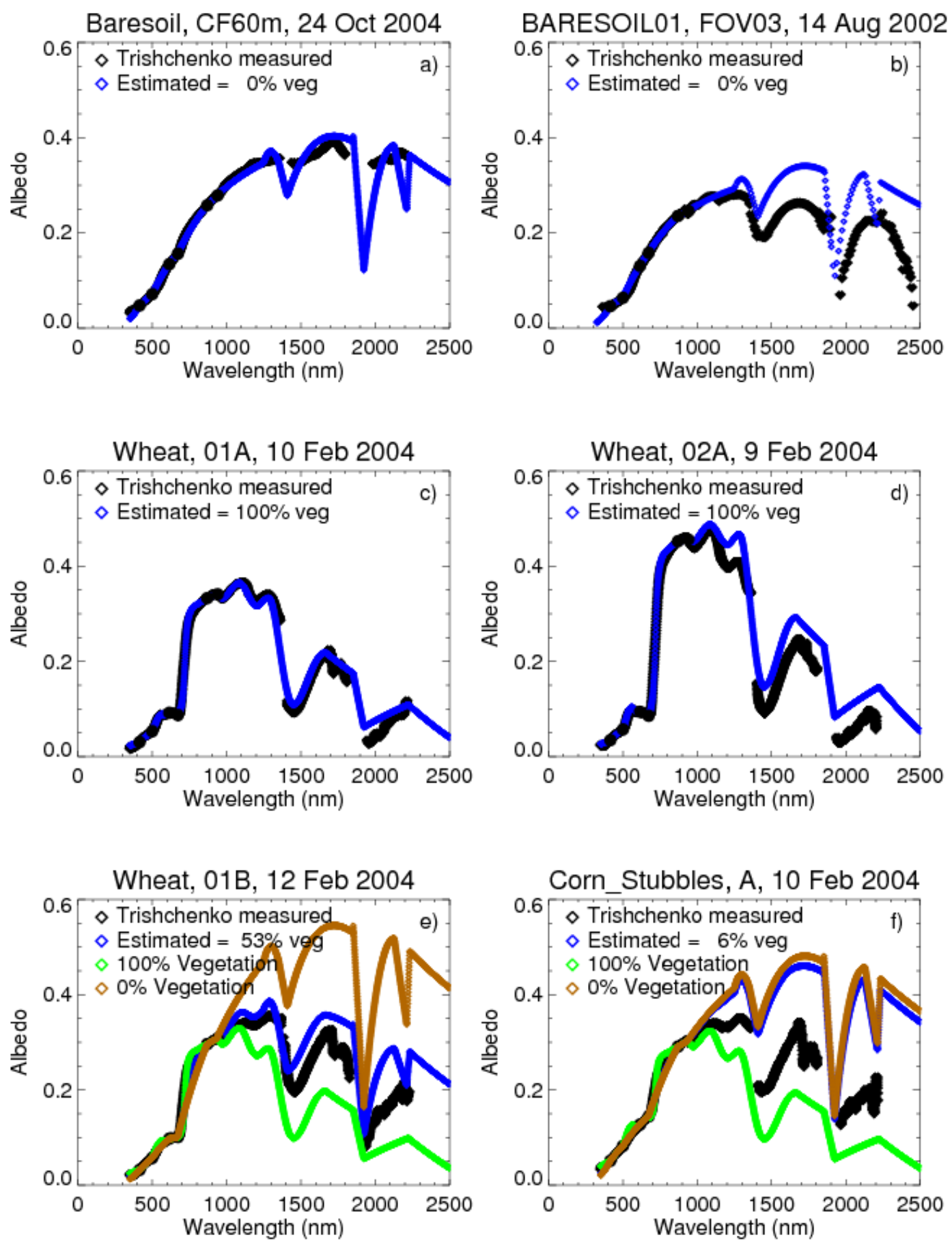

Fig. 5. Examples of spectrally resolved albedo values from (black diamonds) IOP measurements, (blue diamonds) estimation methodology using estimated percent vegetation, (green diamonds) estimation methodology assuming $100 \%$ vegetation, brown diamonds (estimation methodology assuming $0 \%$ vegetation). For cases where the estimated surface type was $0 \%$ or $100 \%$ vegetation, only those estimated values are shown. Cases represent $(\mathbf{a}, \mathbf{b})$ non-vegetated surfaces, $(\mathbf{c}, \mathbf{d})$ fully vegetated surfaces, and $(\mathbf{e}, \mathbf{f})$ partially vegetated surfaces. 

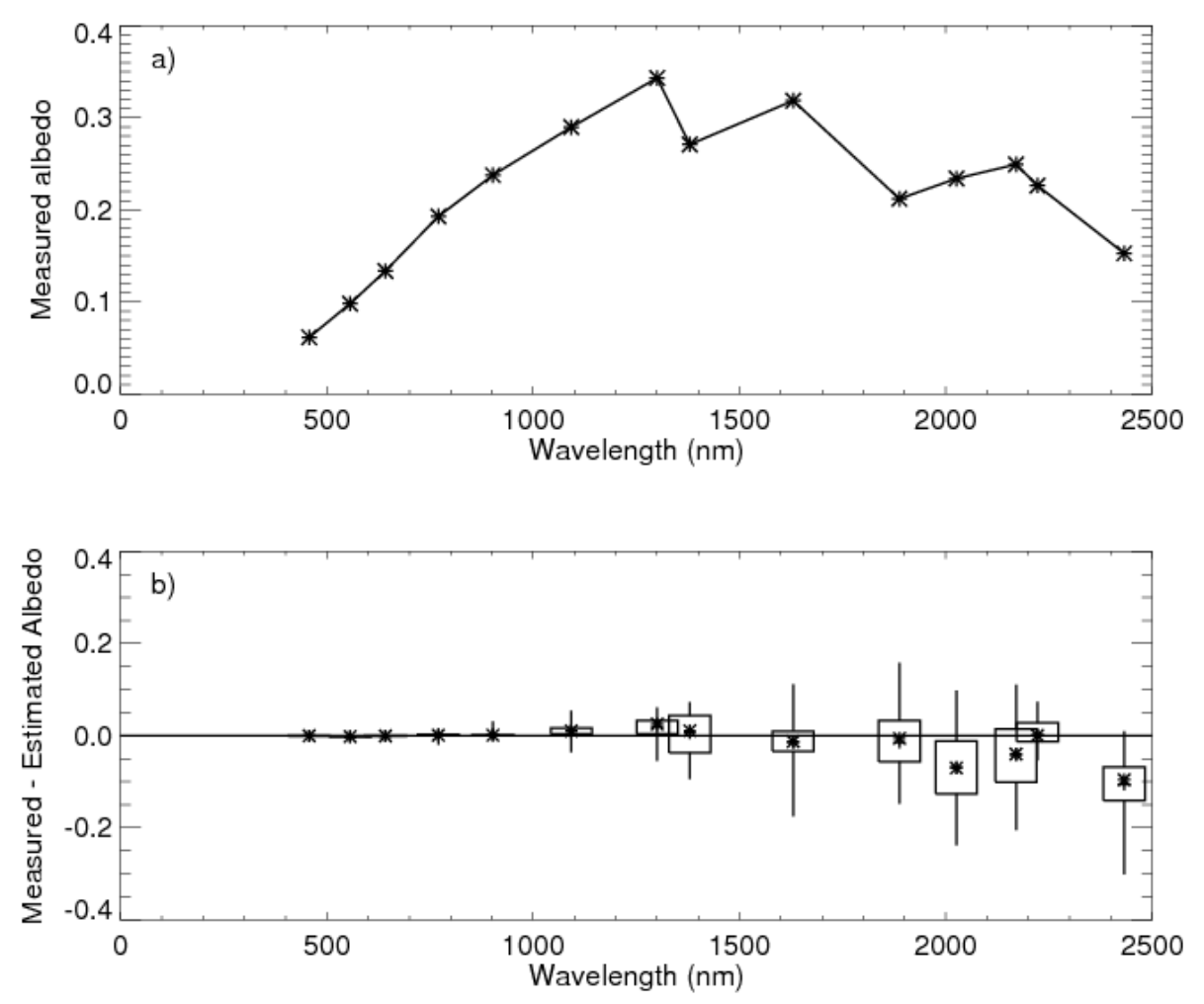

Fig. 6. Evaluation of methodology for all non-vegetated cases during IOP. (a) Average measured albedo within each spectral region and (b) box-whisker diagram showing differences between measured and estimated albedo in each spectral region.

Examination of the statistics of the 26 cases with $100 \%$ vegetation (Fig. 7) shows that there is good agreement, with little bias, between the estimated and measured albedo values up to $1850 \mathrm{~nm}$. For the $1850-1920 \mathrm{~nm}$ region, the method tends to overestimate the measured albedo and for the 2220 2500 region, it tends to underestimate the albedo. All spectral regions have the occasional outlier (large $\mathrm{min} / \mathrm{max}$ values), but mean differences are less than $5 \%$ and relative standard deviation is less than $11 \%$ for regions between $613-$ $1280 \mathrm{~nm}$. The first spectral bin $(313-415 \mathrm{~nm})$ is biased high by $16 \%$ and has a high relative standard deviation (12.6\%), but the albedo values are very low in this region. The 500$613 \mathrm{~nm}$ region also has a large bias (19\% underestimation) and relative standard deviation (16\%). Examination of individual cases shows that the albedo estimation methodology tends to underestimate the peak albedo in this region (which occurs around $550 \mathrm{~nm}$ ) for some of the vegetation cases, although it matches well for others. To improve the albedo estimation in this region, an additional MFR measurement at $550 \mathrm{~nm}$ would be useful.

The estimated albedo methodology produces sharp changes in slope at $1923 \mathrm{~nm}$ and $2232 \mathrm{~nm}$. In some of the observed $100 \%$ vegetation cases, the measured albedos tend to mirror these slope changes, in other cases the observations in this region are quite noisy. The vegetation cases show the general feature of a plateau in the near-infrared between 700 and $1400 \mathrm{~nm}$ associated with leaf cellular structure and water absorption bands centered at 980 and $1240 \mathrm{~nm}$. The exact magnitude of the peaks between 700-1400 nm depend on the characteristics of the vegetation, including cell diameter, number of air/cell interfaces, and leaf water content (Dawson et al., 1998). These characteristics may vary between vegetation types and within the same vegetation type over the growing season. In the extrapolated albedo methodology, these peaks all have approximately the same magnitude, which also occurred in the observed wheat and grass cases. However in some of the other vegetation cases the $3 \mathrm{rd}$ peak was lower in magnitude than the first peak (soybean and milo cases). Examples of spectral albedo from other measurement campaigns (e.g., Liang et al., 2002) indicate that the behavior of vegetation in the 700-1400 $\mathrm{nm}$ region can vary considerably. The MFR has two measurements (at 873 and $940 \mathrm{~nm}$ ) that constrain the magnitude of the first peak; having additional measurements (at 1100 and $1300 \mathrm{~nm}$ ) would help constrain the magnitude of the other two peaks.

\subsubsection{Partially vegetated surfaces}

As expected, the estimated albedo is more uncertain for the partially vegetated cases. Figure $5 \mathrm{e}$ illustrates a wheat field observed on 12 February 2004, which is retrieved as $53 \%$ vegetation. In this plot, the estimated curves for $0 \%$ and 
$100 \%$ vegetation are also shown. Clearly, the partial vegetation estimate is a better fit than either the $0 \%$ or $100 \%$ vegetation estimates. The magnitude of the albedo is fairly well matched up to $1400 \mathrm{~nm}$, but then the estimated albedo has a weaker absorption feature at $1400 \mathrm{~nm}$ and overestimates the albedo beyond $1400 \mathrm{~nm}$. The shape of the estimated albedo is also not a very good match beyond $1900 \mathrm{~nm}$. In the second case (Fig. 5f), corn stubble observed on 10 February 2004, a percent vegetation of $6 \%$ is retrieved, which appears to be too low when examining the observed spectral albedo. Since the percent vegetation is so low, the shape of the estimated albedo is dominated by the $0 \%$ vegetation curve and is also not a good match.

The 45 partial vegetation cases (Fig. 8) show good agreement between 415 and $1280 \mathrm{~nm}$, with mean differences $<7 \%$ and relative standard deviation $<8 \%$, but tend to overestimate the measured albedo for wavelengths greater than $1280 \mathrm{~nm}$, except in the band at $1852-1923 \mathrm{~nm}$ where the mean difference is $<2 \%$ although the variability is significant. The overestimate at longer wavelengths may be due an underestimate of the percent vegetation (as seen in Fig. 5f) as soil tends to have higher albedo beyond $1200 \mathrm{~nm}$ than vegetated surfaces do. An MFR measurement beyond $1200 \mathrm{~nm}$ could help constrain the percent vegetation and the albedo values at these longer wavelengths.

\subsection{Comparison to broadband albedo measurements}

As a further evaluation of the albedo estimation methodology, we examine differences between the broadband albedo calculated from integrating the high spectral resolution albedo and that measured by the broadband PSP instruments. Given a specification of spectral surface albedo values such as described in the previous section, a corresponding broadband albedo $\alpha_{\mathrm{BB}}$ can be defined by

$\alpha_{\mathrm{BB}}=\frac{\int \alpha_{\lambda} S_{\lambda} \mathrm{d} \lambda}{\int S_{\lambda} \mathrm{d} \lambda}$

where $\alpha_{\lambda}$ are the spectral albedo values and $S_{\lambda}$ are the spectral downwelling solar irradiances at the surface. The $S_{\lambda}$ values serve as weights for the integration of the spectral albedo values, indicating that the same surface will have different broadband albedos should the atmospheric conditions result in different relative spectral distributions of solar irradiance reaching the surface. The spectral downwelling irradiance at the surface differs from the incoming spectral irradiance spectrum at the top of the atmosphere due to spectrally dependent absorption and scattering of solar radiation in the atmosphere. Among the atmospheric properties that can have an important impact on the relative attenuation of solar radiation are the amount of water vapor (the greatest source of absorption) and scattering by aerosols, clouds, and molecules. In addition, a change in solar zenith angle may result in a modified spectral distribution of surface solar irradiance even if the atmospheric properties are unchanged.
There are no appropriate spectral measurements of surface solar irradiance, $S_{\lambda}$, at SGP, and radiative transfer calculations of $S_{\lambda}$ for each case would be computationally prohibitive. Instead, we apply Eq. (4) utilizing $S_{\lambda}$ values obtained from a high-resolution radiative transfer calculation for a single case associated with atmospheric conditions typical for SGP. In particular, we use a calculation by the Lineby-Line Radiative Transfer Model (LBLRTM) and Code for High resolution Accelerated Radiative Transfer and Scattering (CHARTS) (Clough et al., 2005) for 4 May 2000, 15:48 UT, at SGP. This case, which was utilized for a recent radiation code intercomparison (Oreopoulos and Mlawer, 2010), corresponds to clear-sky conditions with a solar zenith angle of 40.6 and water vapor column amount and aerosol optical depths typical for the site. This ensures that the relative spectral distribution of calculated surface irradiance will be reasonably typical, providing some universality to the shape of the spectrum used in the weighting.

We examine the difference between the integrated albedo and measured broadband albedo from the PSPs at each tower for near-noon values for each day between 2003-2008 for which a valid surface type and valid PSP measurements exist (Fig. 9 and Table 3). The albedo values calculated from measured irradiance values, calculated from estimated irradiance values, and estimated from near-noon albedo values are plotted separately. In general, the agreement between the integrated and measured broadband albedos is good, with mean and median residuals less than 0.01 and standard deviation less than 0.015 for both towers (Table 3 ). There is some dependence on vegetation type, with $100 \%$ vegetation having the smallest mean residuals at both towers, but the largest standard deviation at the $10 \mathrm{~m}$ tower. At the $10 \mathrm{~m}$ tower, the integrated values slightly underestimates the PSP broadband albedo, while the opposite is true at the $25 \mathrm{~m}$ tower.

Several outliers are obvious in both the $10 \mathrm{~m}$ and $25 \mathrm{~m}$ cases. We first examined whether the outliers were caused by cases where the MFR narrowband albedos were estimated due to missing irradiance or albedo values (purple and orange points in Fig. 9). These estimated points do have larger standard deviation than the non-estimated points, but similar means ("Estimated" points in Table 3), and they do not account for all of the large outliers. Further analysis of the individual points with residuals greater than 0.1 indicated that they were all due to problems with the input data sets that were not caught during the initial quality control checks. Cases with residuals between 0.05 and 0.1 were typically associated with either bad input data, cases of broken clouds (where rapid changes in direct irradiance and the spatial separation of the downwelling and upwelling instruments can cause noise in the albedo values), or cases with broadband downwelling irradiance $<200 \mathrm{Wm}^{-2}$.

The above analysis indicates that the comparison of integrated to measured broadband albedo could be useful as a quality control check to identify additional problems with the input datasets or periods where the albedo methodology 

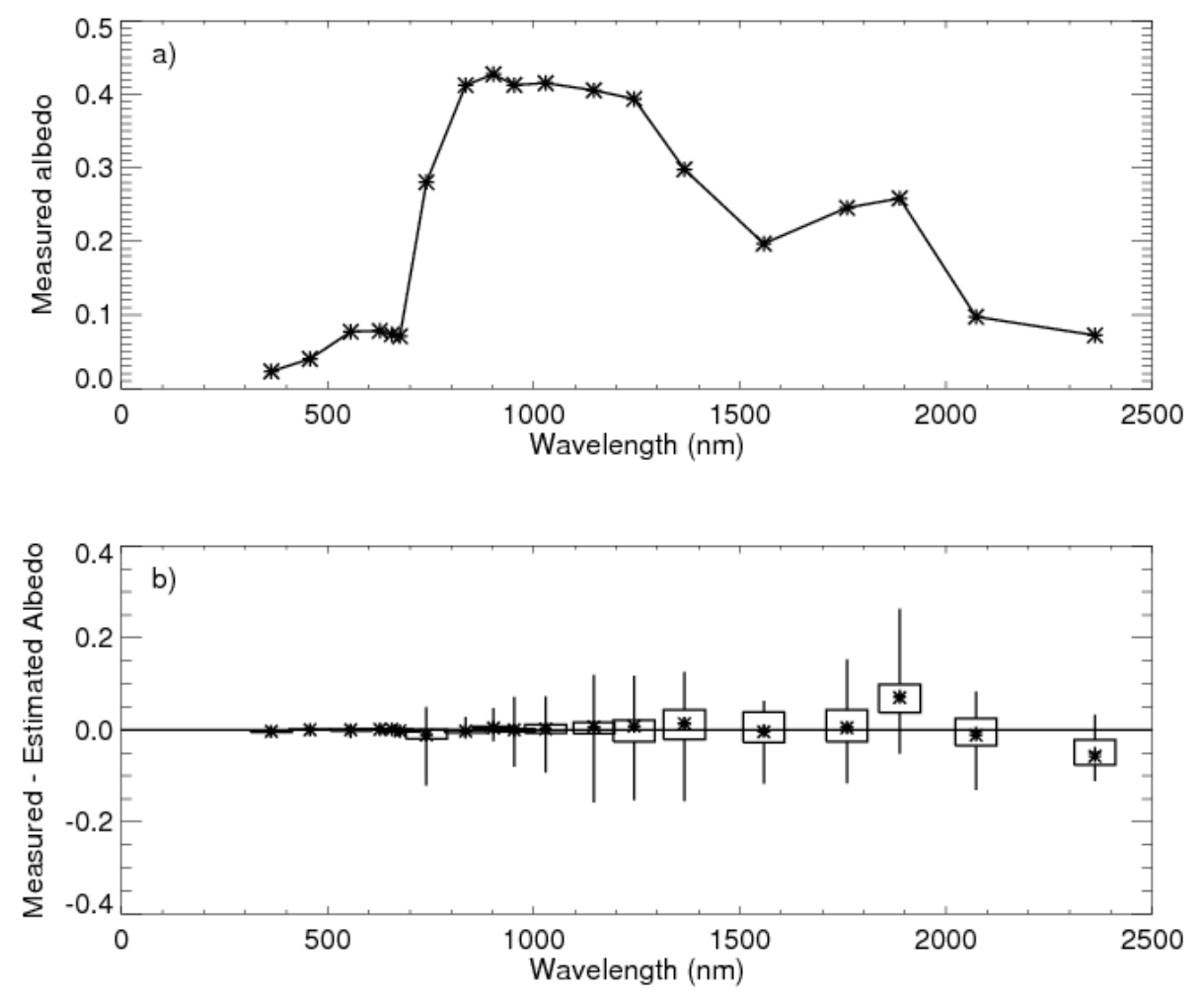

Fig. 7. Evaluation of methodology for all $100 \%$ vegetation cases during IOP. (a) Average measured albedo within each spectral region and (b) box-whisker diagram showing differences between measured and estimated albedo in each spectral region.
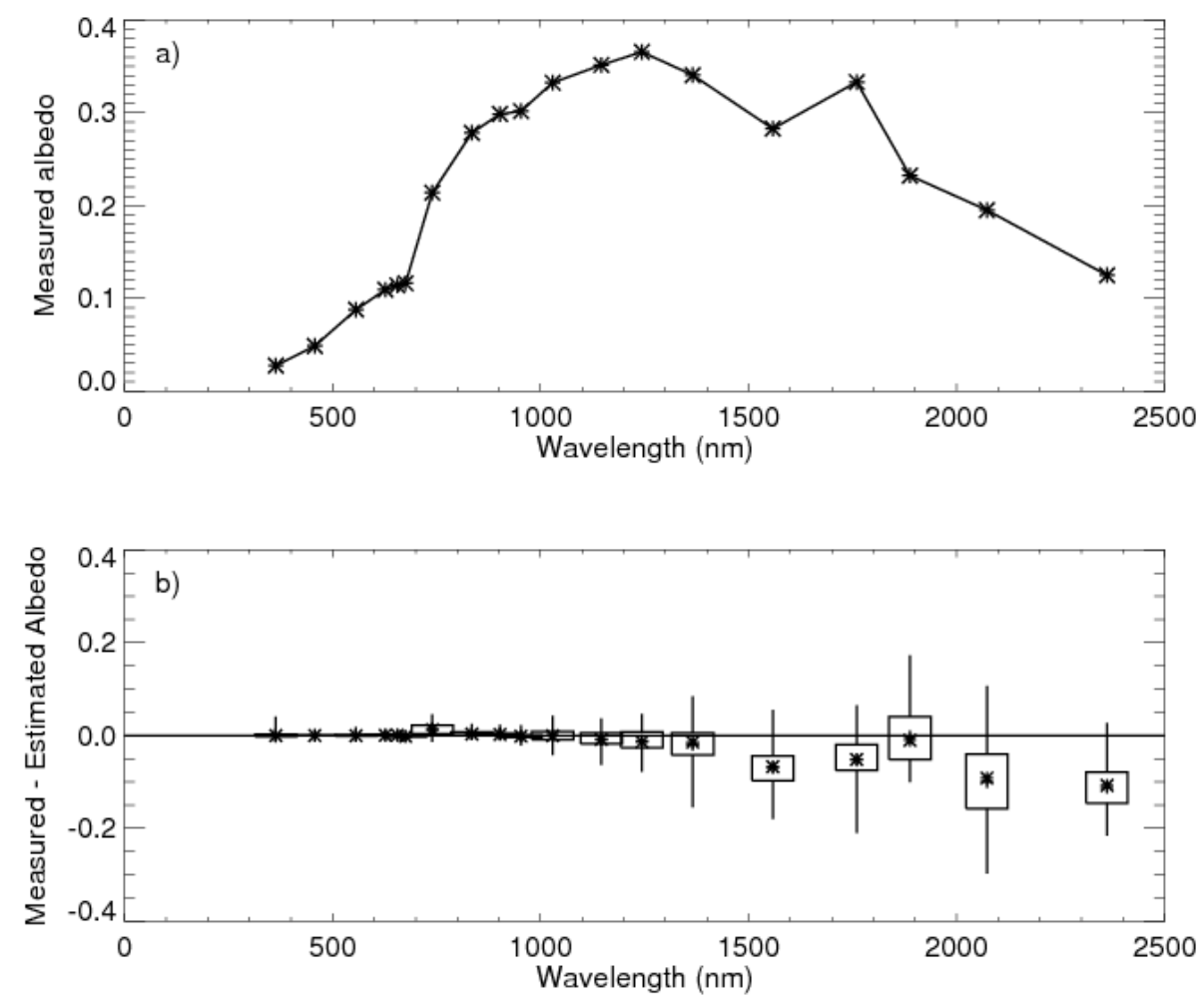

Fig. 8. Evaluation of methodology for all partially vegetated cases during IOP. (a) Average measured albedo within each spectral region and (b) box-whisker diagram showing differences between measured and estimated albedo in each spectral region. 
Table 3. Mean, median, and standard deviation of differences between broadband albedo values calculated from integrating spectral albedo or measured from the PSPs.

\begin{tabular}{lrrrr}
\hline \multicolumn{5}{c}{10 m near-noon residuals (Integrated - PSP) } \\
\hline Type & \# points & mean & median & standard dev \\
\hline All points & 2159 & -0.0074 & -0.0082 & 0.0136 \\
$100 \%$ veg & 510 & -0.0010 & -0.0100 & 0.0177 \\
Partial veg & 851 & -0.0058 & -0.0080 & 0.0115 \\
$0 \%$ veg & 655 & -0.0089 & -0.0010 & 0.0130 \\
Estimated & 192 & -0.0078 & -0.0080 & 0.0194 \\
\hline
\end{tabular}

$25 \mathrm{~m}$ near-noon residuals (Integrated - PSP)

\begin{tabular}{lrrrr}
\hline Type & \# points & mean & median & standard dev \\
\hline All points & 2159 & 0.0066 & 0.0063 & 0.0148 \\
$100 \%$ veg & 543 & 0.0042 & 0.0039 & 0.0138 \\
Partial veg & 1099 & 0.0088 & 0.0089 & 0.0144 \\
$0 \%$ veg & 282 & 0.0084 & 0.0113 & 0.0207 \\
Estimated & 195 & 0.044 & 0.0063 & 0.0242 \\
\hline
\end{tabular}

is not appropriate. In the final albedo dataset, times with broadband residuals greater than 0.05 but less than 0.1 are flagged as indeterminate and times with broadband residuals equal to or greater than 0.1 are flagged as bad.

\subsection{Effects of cloud cover and solar zenith angle}

Although the intrinsic albedo of the surface does not change with cloud cover, the measured albedo may be different under clear sky and cloudy conditions because spectrallyvarying absorption and scattering of radiation by clouds may change the percentage of radiation incident on the surface in each spectral region relative to the clear sky insolation (Liang et al., 1999). Additionally, cloud cover affects the average angle of solar insolation on the surface. Under clear skies, the solar insolation at the surface is from a narrow range of angles (direct radiation) while under cloudy conditions solar insolation at the surface is diffuse (radiation incident on the surface from multiple angles). Since most natural surfaces do not scatter isotropically, cloud cover changes the angular weighting of the surface reflectance relative to that under clear skies. In the current work, no correction for cloud cover has been implemented.

To evaluate the effect of cloud cover on the spectral albedo estimates, we examine our multi-year record of estimated albedos in concert with a hemispheric cloud fraction dataset determined from broadband radiometer measurements (Long and Ackerman, 2000). A comparison between the integrated spectral albedo and the measured broadband albedo for all of the 1 min retrievals from 2004-2008 (close to a million points for each tower) shows no clear dependence on cloud cover (Fig. 10). The scatter appears wider at $0 \%$ and $100 \%$ cloud fraction primarily because of the much larger number of points that are completely clear or completely overcast. Note that for Figs. 10 and 11, we use the final albedo dataset, in which points with residuals having magnitudes greater than 0.1 have been removed.

To further examine the role of cloud fraction, we break the cloud fraction down into 11 bins, each with width of 0.1 , and examine the residuals in each bin (Fig. 10). The first bin is centered on a cloud fraction of zero and the last bin centered on cloud fraction of one. Approximately $27 \%$ of the data is in the first cloud fraction bin and $28 \%$ in the last cloud fraction bin with the other bins each containing between 3.2 and $8.1 \%$ of the data. For all cloud fraction bins, the median residual and the values of the 25 th and 75 th quartiles are very similar, although the minimum and maximum values of the residual vary somewhat with cloud fraction. The albedo values calculated from estimated irradiances show more variability with cloud fraction, with slightly larger mean residuals for overcast clouds than for other cloud conditions. Despite the potential effect of clouds on surface albedo conditions discussed above, we find little dependence of the residuals on cloud fraction. Possible reasons for the lack of dependence on cloud cover are that both the narrowband MFR albedos and the broadband PSP albedos are measured under the same cloudiness conditions or that the effects of cloud cover may be smaller than other sources of error in the comparison of the integrated and measured albedos.

Surface albedo is dependent on solar zenith angle during non-overcast conditions, because of the contribution of the direct solar beam (Liang, 2000). However, since we are estimating the spectral albedo for the same solar zenith angles at which the MFR albedo measurements are taken, the blend of direct and diffuse radiation at that instant is taken into account and we do not expect significant errors in the extrapolated albedo due to solar zenith angle dependence. To examine the effect of solar zenith angle on the estimated spectral albedo, we again compare the integrated spectral albedo to the measured broadband albedo (Fig. 11) as a function of $\mu_{0}$. Here we split $\mu_{0}$ into 8 bins between 0.20 and 1.0 with bin width of 0.10. (For consistency with the cloud fraction dataset, which does not have values for $\mu_{0}<0.2$ we only include points with $\mu_{0}>0.2$ in this analysis). We see only a slight dependence on solar zenith angle, with larger variability for cases of lower sun angles near sunrise and sunset. We note that the first bin (low sun angles) has only $6.7 \%$ of the data and has the largest variability while the other bins each contain between 10.2 to $16.0 \%$ of the data.

The set of points with large residuals and $\mu_{0} \sim 0.5$ are caused primarily by a subset of days that are clumped together and are often caused by the same days at both towers. Analysis of one of these periods (18 November to 9 December 2006) found an ARM data quality report indicating some issues in the upwelling broadband SW measurement at the SIRSC1 instrument. Because there are only two broadband SW upwelling measurements, it can sometimes be difficult 

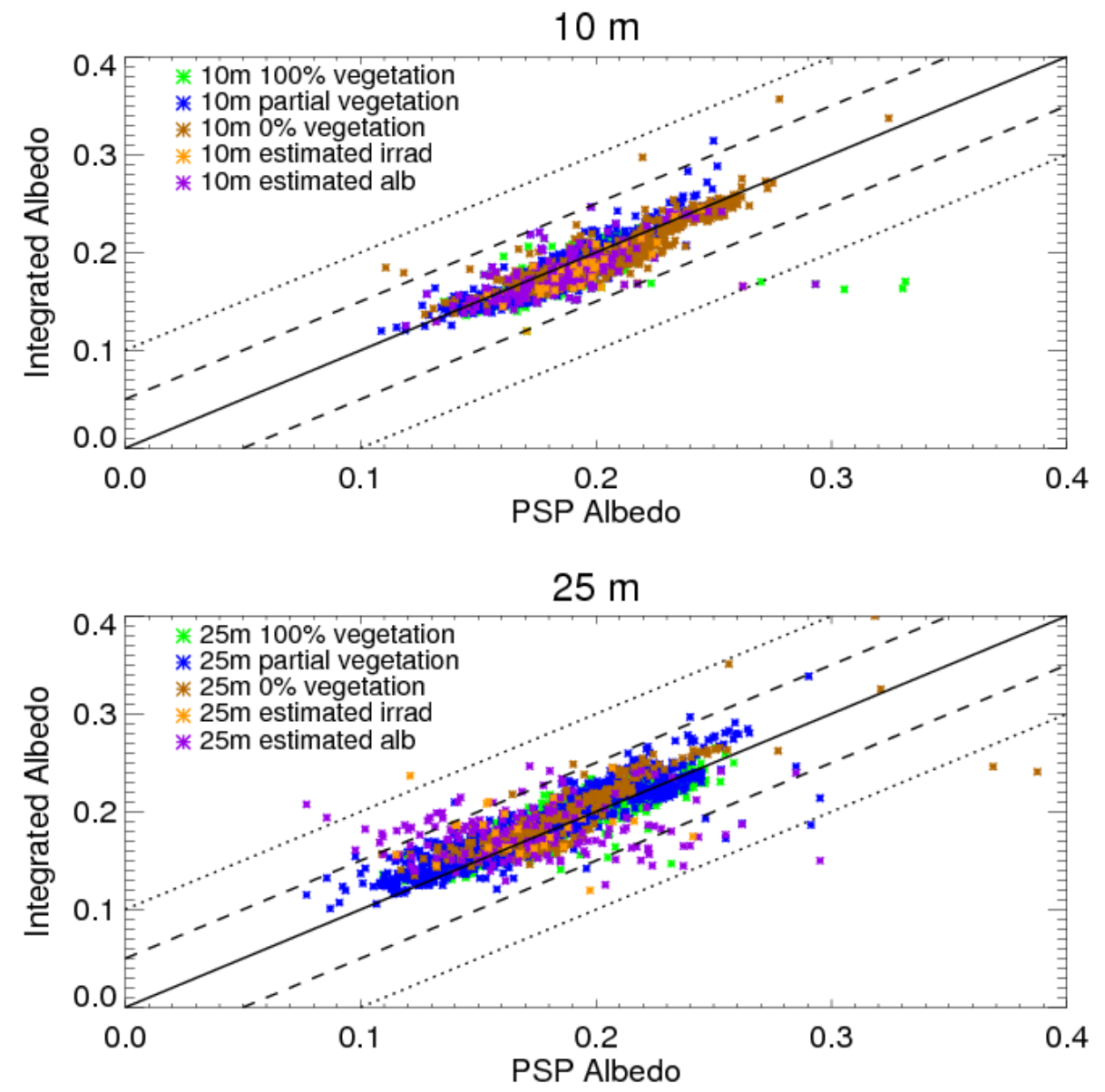

Fig. 9. Comparison of integrated spectral albedo to measured broadband albedo near noon for (top) $10 \mathrm{~m}$ tower measurements and (bottom) $25 \mathrm{~m}$ tower measurements. Surface type and mean, median, standard deviations of differences (measured-integrated) are given in the plots. Points for which irradiance values (orange) or albedo values (purple) are estimated are also indicated.

for the BEFlux algorithm to identify the bad instrument, and it appears that some bad data may not have been flagged in this case.

\section{Impact of spectrally resolved surface albedo}

To illustrate the impact of employing a spectral specification of surface albedo instead of a broadband value for clearsky solar irradiance calculations, we perform two spectrallydetailed solar radiative transfer calculations (Fig. 12). Radiative transfer calculations using the LBLRTM/CHARTS model were performed for conditions corresponding to those observed in the afternoon of 4 May 2000, at the SGP site. This is the same case used for the spectral integration in Part 4. First, a line-by-line radiative transfer calculation using the spectral surface albedo for $100 \%$ vegetation (panel a) was performed (black curves in panels $b$ and $d$ ). The spectral albedo was then integrated to obtain a broadband albedo and this spectrally constant broadband value was used in a second line-by-line radiative transfer calculation (red curves in panel $b$ and d) while all other inputs to the model were the same as in the first calculation. By construction, the two calculations produced the same spectrally integrated upwelling irradiance at the surface due to the identical broadband surface albedo values employed, although the two corresponding spectral distributions of upwelling irradiance differed significantly (not shown).

For the surface downwelling irradiance (panel c) and topof-the-atmosphere (TOA) upwelling irradiance (panel e), the spectrally integrated values are not equal due to correlations between the spectral behavior of the surface upwelling irradiance and various atmospheric radiative processes. For example, in the visible and ultraviolet (UV) spectral regions the surface albedo is less than its average value while the optical depth due to Rayleigh scattering is far greater than in other spectral regions. Therefore, in this region, the diffuse component of the downwelling surface irradiance is lower in the calculation that uses a spectral albedo due to a decrease in visible and UV radiation that passes completely through the atmosphere once, is reflected off the surface, and 


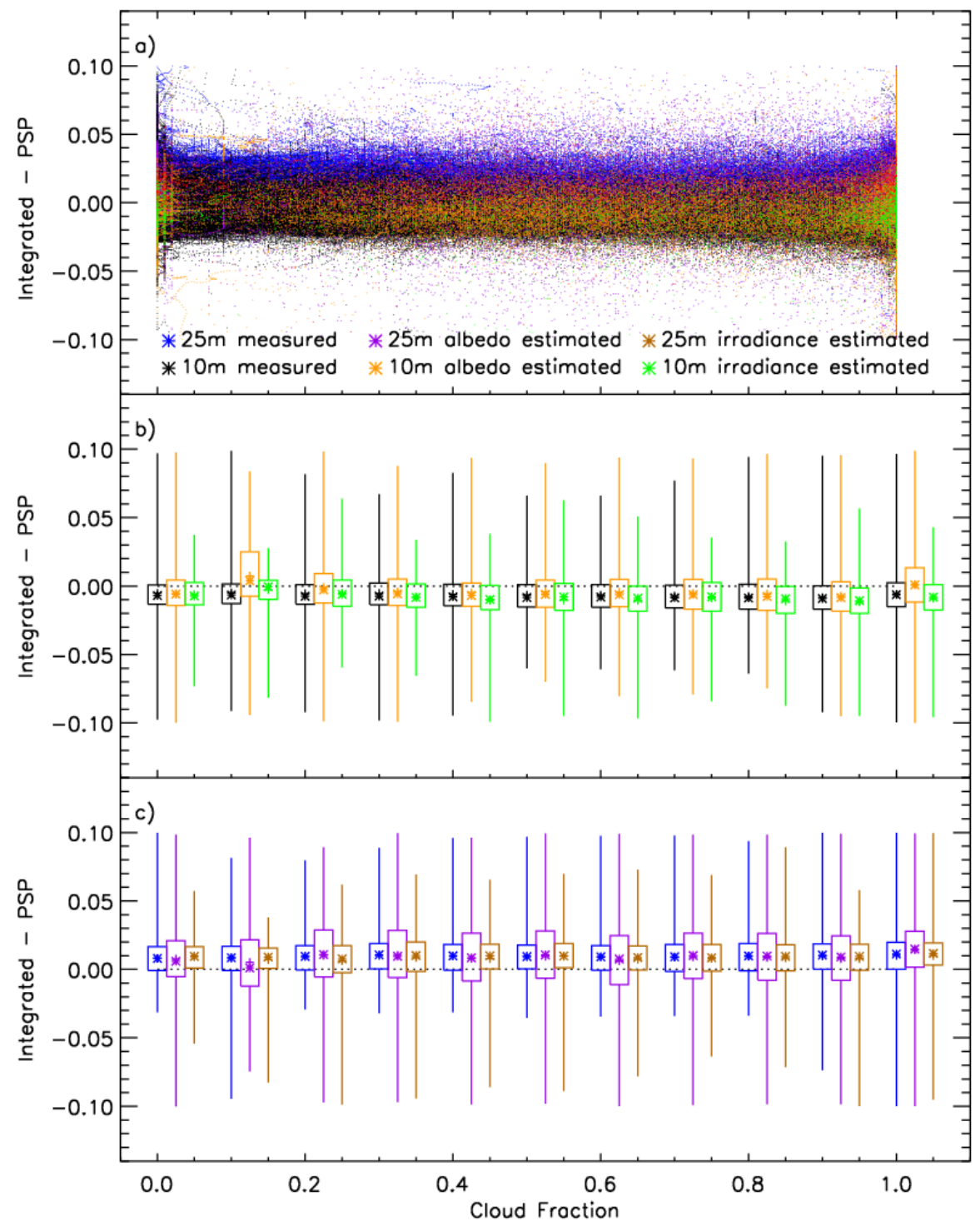

Fig. 10. Broadband albedo residual (integrated spectral minus measured PSP albedo) as a function of cloud fraction for the period 20042008. Residuals are plotted separately for points for which albedo is directly measured (black and blue symbols), albedo is estimated due to missing or bad values (purple and orange) and albedo is calculated from estimated irradiances (brown and green). Panels show (a) $10 \mathrm{~m}$ and $25 \mathrm{~m}$ individual values, (b) box-whisker plot for $10 \mathrm{~m}$ values, and (c) box-whisker plot for $25 \mathrm{~m}$ values.

then is back-scattered to the ground by Rayleigh scattering. This decrease in diffuse radiation is not fully compensated for by increases in diffuse radiation in other spectral regions where the surface albedo is relatively high, resulting in a net $6.6 \mathrm{Wm}^{-2}$ decrease in the integrated downwelling irradiance computed using the spectral albedo. From this analysis, it is clear that the use of a spectrally constant surface albedo was an important factor in past studies (e.g., Halthore et al., 2005) that concluded that radiative transfer models overestimated diffuse irradiance for clear sky conditions, in contrast to those studies that used a spectrally varying surface albedo and found no such discrepancy (e.g., Michalsky et al., 2006).

\section{Discussion and conclusions}

We have presented a method for identifying surface type and estimating spectral albedo at the surface given a set of 6-channel MFR albedo measurements. Four different surface types (snow-covered, green vegetation, partial vegetation, non-vegetated) can be identified from the current MFR wavelengths. The NDVI was used to distinguish between vegetated and non-vegetated surfaces, and a scaled NDVI index was used to estimate the percentage of green vegetation in partially vegetated surfaces. Based on libraries of spectral albedos, piecewise continuous functions were developed to estimate the high spectral resolution albedo for 


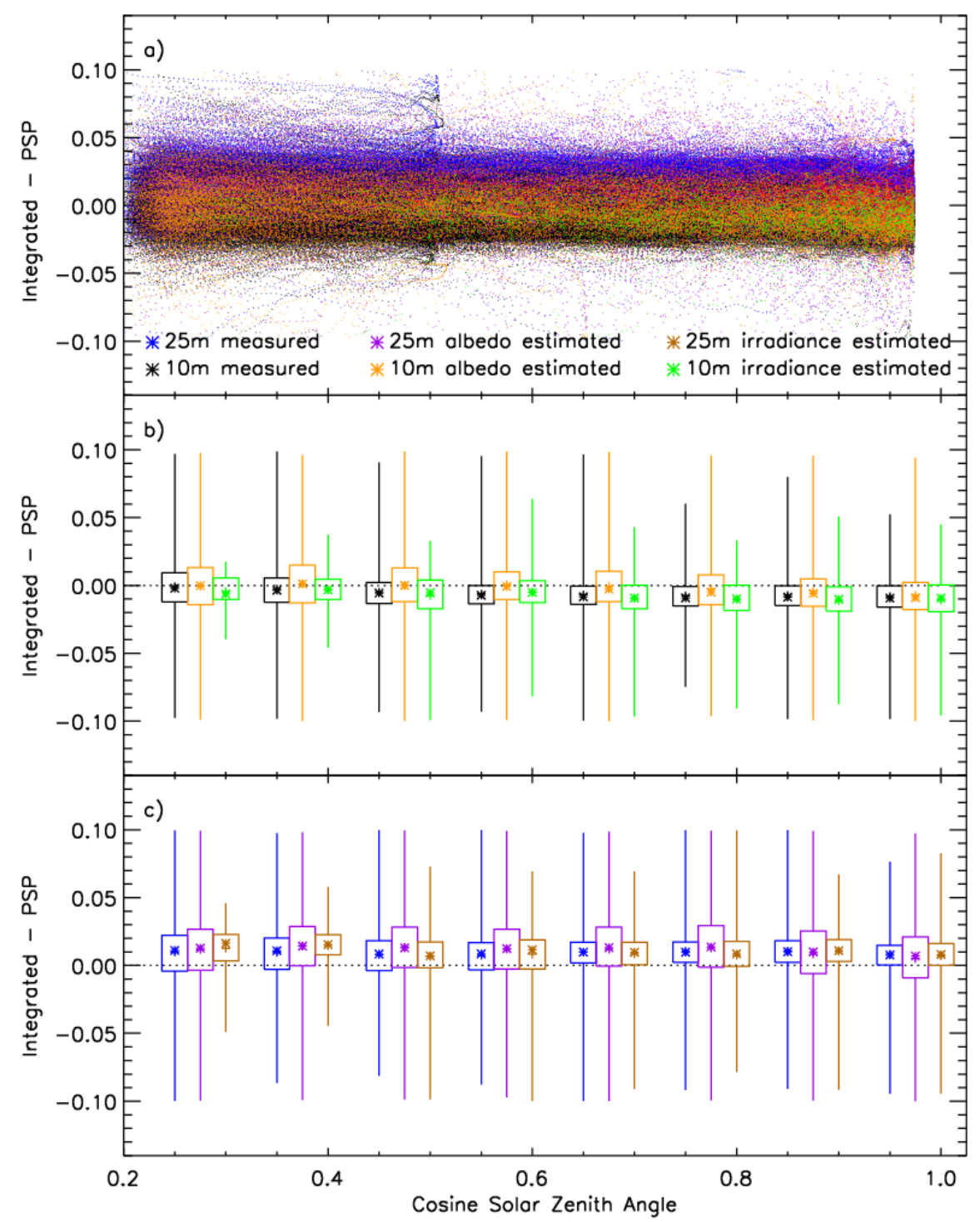

Fig. 11. As in Fig. 10, but residuals are plotted as a function of the cosine of the solar zenith angle.

each surface type given the input MFR narrowband albedos. For partially vegetated surfaces, the albedo was estimated as a linear combination of the green vegetation and nonvegetated surface albedo values. The final dataset, named sgpsurfspecalb1mlawerC1, includes the daily surface type and the quality-controlled MFR and MFRSR narrowband irradiances and albedos, estimated spectral albedo, integrated broadband albedos and various quality control flags at 1min resolution. It is freely available from the ARM archive (www.archive.arm.gov).

The estimated spectral albedos were evaluated by comparison to measurements from four intensive observation periods undertaken at the SGP site. The estimated albedo values were in reasonably good agreement (mean differences $<7 \%$ and relative standard deviation $<11 \%$ ) for all surface types for spectral regions between 613-1280 nm. Beyond this range, where MFR measurements were not available to constrain the retrieval, the behavior varied by surface type. For non-vegetated surfaces, mean differences were still $<7 \%$ up to $1920 \mathrm{~nm}$, but variability became significantly larger. Beyond $1920 \mathrm{~nm}$, the methodology tended to overestimate the observed values. Vegetated surfaces showed small biases for most spectral regions, except albedo was overestimated on average between $313-415 \mathrm{~nm}$ and $1850-1920 \mathrm{~nm}$, while it was underestimated in the 500-613 nm and $2220-2250 \mathrm{~nm}$ regions. Partial vegetation cases showed large overestimates of albedo beyond $1280 \mathrm{~nm}$, which may be due to underestimate in the percent vegetation. 

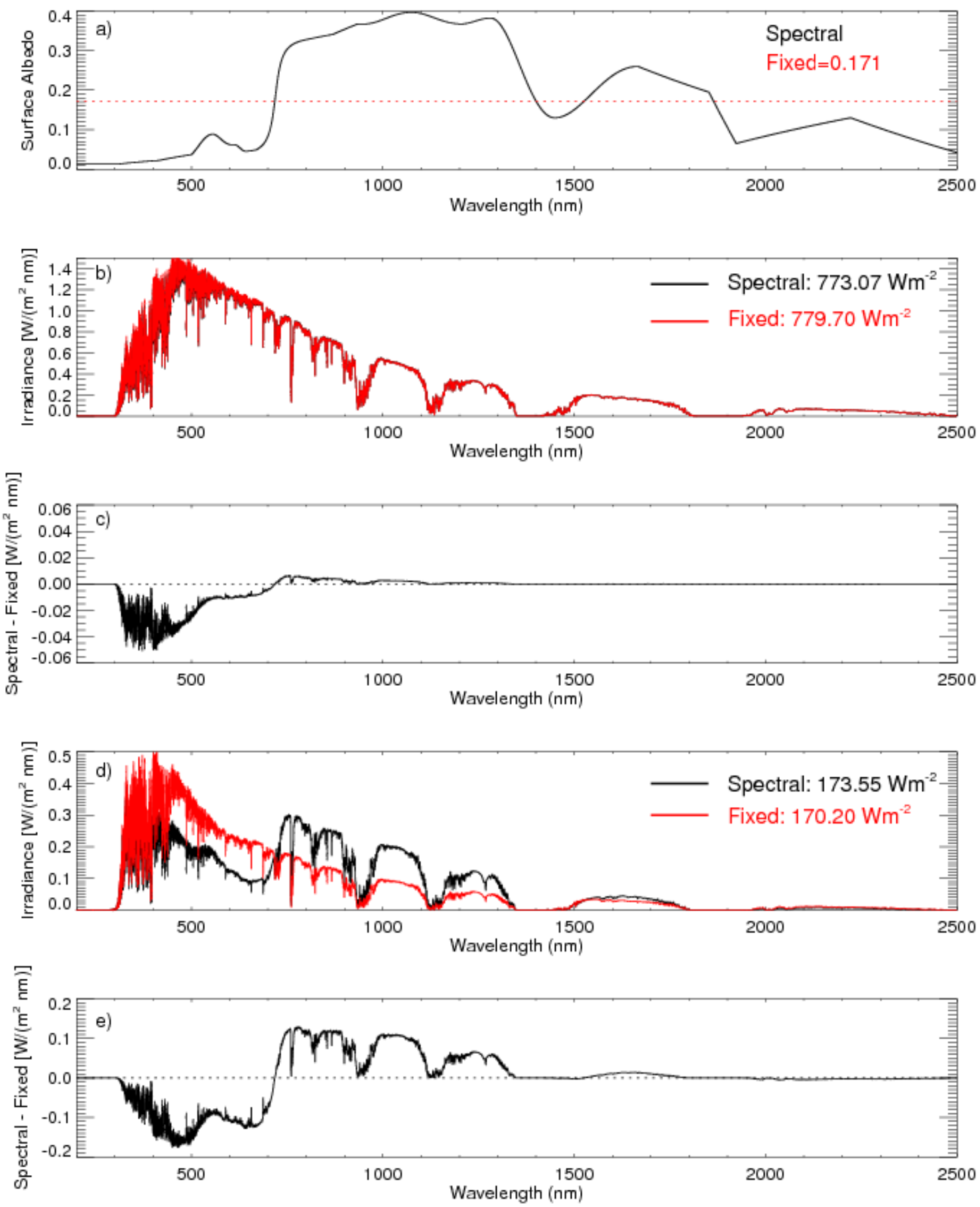

Fig. 12. Results of calculations using LBLRTM/CHARTS with spectrally varying and fixed albedo for the 4 May 2000 case. Panels show (a) spectrally varying and fixed albedo used in calculations, (b) calculated downwelling irradiance at the surface, (c) irradiance difference (spectral - fixed albedo) at the surface, (d) calculated upwelling irradiance at the top of the atmosphere, and (e) irradiance difference (spectral fixed albedo) at the top of the atmosphere. The plot is limited to wavelength ranges from $300 \mathrm{~nm}$ to $2500 \mathrm{~nm}$ to emphasize the regions with largest irradiance differences, but the total irradiance across the shortwave spectrum (from 200 to $12000 \mathrm{~nm}$ ) for each calculation is given in the figure legends. 
An additional measurement at a near-IR wavelength would be useful in improving the albedo extrapolation beyond $1000 \mathrm{~nm}$, particularly for vegetated and partially vegetated cases. A $1600 \mathrm{~nm}$ channel has recently been added to several MFR heads at the SGP central facility and the data is currently being analyzed. In future work, we will expand the albedo estimation algorithm to allow input of a $1600 \mathrm{~nm}$ measurement, examine how that improves the spectral estimation at longer wavelengths, and apply the updated algorithm to the new MFR measurements.

As an additional evaluation, the spectral albedos were integrated across the solar spectrum and compared to measured broadband albedos from the measurement towers at the SGP site over several years. For both towers, the agreement between integrated and measured broadband albedo was good, with mean residuals less than 0.01 and standard deviation less than 0.015. Analysis of the residuals as a function of cloud fraction and solar zenith angle found a small dependence on solar zenith angle, with larger variability at lower solar elevations, but no dependence on cloud fraction.

For cloudy sky radiative transfer calculations, the influence of the albedo of the surrounding area should also be taken into consideration. Surface heterogeneity can have a significant impact on the local radiation field, with the area of influence depending on the cloud height (Pirazzini and Raisanen, 2008; Li et al., 2002). In this initial study, we only produce time series of spectrally resolved albedo that are characteristic of the local conditions under each tower. However, by comparing the albedo products derived from the two towers, we can determine periods when the surface heterogeneity (on a 300-m scale) is relatively low. In the next step of product development, we will investigate using cloud height from the ACRF measurements and land-cover or satellite information to combine with the local-scale albedos to produce an arealaverage albedo.

Albedo spectral libraries tend to represent fairly homogeneous surfaces. Due to the small scale nature of the measurements represented in such libraries, they do not capture the effects of surface structure (such as mixed vegetation heights, gaps in vegetation, etc.) on the anisotropy of the reflectance field, which affects the overall albedo. Thus, when using the tower measurements to characterize the albedo of the larger spatial area, information on the bidirectional reflectance function at "landscape-level" scales $(90 \mathrm{~m})$ from aircraft measurements should also be included (Román et al., 2011).

The radiative transfer calculation performed in Sect. 5 showed the importance of using a reasonable specification of the spectrally resolved surface albedo for radiative transfer calculations. The spectral albedos calculated using the methodology described in this paper will be used as input to the ARM Broadband Heating Rate Profiles (BBHRP) and Shortwave Quality Measurement Experiment (SW QME) projects, which compare calculated and measured radiative irradiances to assess our understanding of the various as- pects involved in calculating radiative irradiances. In the current work, the effect of large-scale spatial heterogeneity on the estimated albedo was not considered, and no correction for cloud cover was implemented. As part of the radiative transfer modeling associated with the BBHRP and SW QME projects, the impact of neglecting these factors will be investigated.

Acknowledgements. We thank Alice Cialella for creating and annotating the map of the SGP site. This work was supported by the Department of Energy's Office of Biological and Environmental Research (OBER) as part of the Atmospheric Radiation Measurement (ARM) Program.

Edited by: M. Weber

\section{References}

Baldridge, A. M., Hook, S. J., Grove, C. I., and Rivera, G.: The ASTER Spectral Library Version 2.0, Remote Sens. Environ., 711-715, 1999.

Bowker, D. E., Davis, R. E., Myrick, D. L., Stacy, K., and Jones, W. T.: Spectral reflectances of natural targets for use in remote sensing, Tech. rep., NASA Ref Pub., 1139, 1985.

Carlson, T. N. and Ripley, D. A.: On the relation between NDVI, fractional vegetation cover, and leaf area index, Remote Sens. Environ., 62, 241-252, 1997.

Clough, S. A., Shephard, M. W., Mlawer, E. J., Delamere, J. S., Iacono, M. J., Cady-Pereira, K., Boukabara, S., and Brown, P. D.: Atmospheric radiative transfer modeling: a summary of the AER codes, J. Quant. Spectosc. Radiat. Transfer, 91, 233-244, 2005.

Dawson, T. P., Curran, P. J., and Plummer, S. E.: LIBERTY - Modeling the effects of leaf biochemical concentration on reflectance spectra, Remote Sens. Environ., 65, 50-60, 1998.

Flynn, D. M. and Hodges, G.: Multi-filter Rotating Shadowband Radiometer handbook, Tech. rep., United States Department of Energy, DOE/SC-ARM/TR-059, 2005.

Gardener, A. S. and Sharp, M. J.: A review of snow and ice albedo and the development of a new physically based broadband albedo parameterization, J. Geophys. Res., 115, F01009, doi:10.1029/2009JF001444, 2010.

Halthore, R. N. and Schwartz, S.: Comparison of model-estimated and measured diffuse downward irradiance at surface in cloudfree skies, J. Geophys. Res., 105, 20165-21077, 2000.

Halthore, R. N., Crisp, D., Schwartz, S. E., Anderson, G. P., Berk, A., Bonnel, B., Boucher, O., Chang, F.-L., Chou, M.-D., Clothiaux, E. E., Dubuisson, P., Fomin, B., Fouquart, Y., Freidenreich, S., Gautier, C., Kato, S., Laszlo, I., Li, Z., Mather, J. H., Plana-Fattori, A., Ramaswamy, V., Ricchiazzi, P., Shiren, Y., Trishchenko, A., and Wiscombe, W.: Intercomparison of shortwave radiative transfer codes and measurements, J. Geophys. Res., 110, D11206, doi:10.1029/2004JD005293, 2005.

Henderson-Sellers, A. and Wilson, M. F.: Surface albedo data for climatic modeling, Rev. Geophys., 21, 1743-1778, 1983.

Jiang, Z., Huete, A. R., Chen, J., Chen, Y., Li, J., Yan, G., and Zhang, X.: Analysis of NDVI and scaled difference vegetation index retrievals of vegetation fraction, Remote Sens. Environ., 101, 366-378, 2006. 
Kustas, W. P., Schumugge, T. J., Jumes, K. S., Jackson, T. H., Parry, R., and Weltz, M. A.: Relationships between evaporative fraction and remotely sensed vegetation index and microwave brightness temperature for semiarid rangelands, J. Appl. Met., 32, 17811790, 1993.

Li, Z., Cribb, M. C., and Trishchenko, A. P.: Impact of surface inhomogeneity on solar radiative transfer under overcast conditions, J. Geophys. Res., 116, 4294, doi:10.1029/2001JD000976, 2002.

Liang, S.: Narrowband to broadband conversions of land surface albedo: 1. Algorithms, Remote Sens. Environ., 76, 213-238, 2000.

Liang, S., Stahler, A., and Walthall, C.: Retrieval of land surface albedo from satellite observations: A simulation study, J. Appl. Meteorol., 38, 712-725, 1999.

Liang, S., Fang, H., Chen, M., Shuey, C. J., Walthall, C., Daughtry, C., MOrisette, J., Schaaf, C., and Strahler, A.: Validating MODIS land surface reflectance and albedo products: methods and preliminary results, Remote Sens. Environ., 83, 149-162, 2002.

Lobell, D. B. and Asner, G. P.: Moisture effects on soil reflectance, Soil Sci. Soc. Am. J., 66, 722-727, 2002.

Long, C. N. and Ackerman, T. P.: Identification of clear skies from broadband pyranometer measurements and calculation of downwelling shortwave cloud effects, J. Geophys. Res., 105, 1560915626, 2000.

McFarlane, S. A. and Evans, K. F.: Clouds and shortwave fluxes at Nauru. Part I: retrieved cloud properties, J. Atmos. Sci., 61, 733-744, 2004.

McFarlane, S., Gaustad, K., Long, C., and Mlawer, E.: ARM Climate Research Facility Spectral Surface Albedo Value-Added Product (VAP) Report, DOE/SC-ARM/TR-096, 2011.

Michalsky, J., Min, Q., Barnard, J., Marchand, R., and Pilewski, P.: Simultaneous spectral albedo measurements near the Atmospheric Radiation Measurement Southern Great Plains (ARM SGP) central facility, J. Geophys. Res., 108, D4254, doi:10.1029/2002JD002906, 2003.

Michalsky, J., Anderson, G. P., Barnard, J., Delamere, J., Gueynard, C., Kato, S., Kiedron, P., McComiskey, A., and Ricchiazzi, P.: Shortwave radiative closure studies for clear skies during the Atmospheric Radiation Measurement 2003 Aerosol Intensive Observation Period, J. Geophys. Res., 111, D14S90, doi:10.1029/2005JD006341, 2006.

Mlawer, E. J., Brown, P. D., Clough, S. A., Harrison, L. C., Michalsky, J. J., Kiedron, P. W., and Shippert, T.: Comparison of spectral direct and diffuse solar irradiance measurements and calculations for cloud-free conditions, Geophys. Res. Lett., 27, 26532656, 2000.

Myneni, R. B., Hall, F. G., Sellers, P. J., and Marshak, A. L.: The interpretation of spectral vegetation indexes, IEEE T. Geosci. Remote Sens., 33(2), 481-486, 1995.
Oreopoulos, L. and Mlawer, E.: The Continual Intercomparison of Radiation Codes (CIRC), B. Am. Meteorol. Soc., 91, 305-310, doi:10.1175/2009BAMS2732.1, 2010.

Pirazzini, R. and Raisanen, P.: A method to account for surface albedo heterogeneity in single-column radiative transfrer calculations under overcast conditions, J. Geophys. Res., 113, D20109, doi:10.1029/2008JD009815, 2008.

Román, M. O., Gatebe, C. K., Schaaf, C. B., Poudyal, R., Wang, Z., and King, M. D.: Variability in surface BRDF at different spatial scales (30 m-500 m) over a mixed agricultural landscape as retrieved from airborne and satellite spectral measurements, Remote Sens. Environ., 115, 2184-2203, 2011.

Schaaf, C. B., Gao, F., Strahler, A. H., Lucht, W., Li, X. W., Tsang, T., Strugnell, N., Zhang, X. Y., Jin, Y. F., Muller, J. P., Barnsley, M., Hobson, P., Disney, M., Roberts, G., Dunderdale, M., Doll, C., D'Entremont, R. P., Hu, B. X., Liang, S. L., and Privette, J. L.: First operational BRDF, albedo and nadir reflectance products from MODIS, Remote Sens. Environ., 83, 135-148, 2002.

Shi, Y. and Long, C. N.: Best estimate radiation flux Value Added Product: Operational details and explanations, Tech. rep., US Department of Energy, DOE/SC-ARM/TR-008, 2002.

Trishchenko, A. P., Luo, Y., Cribb, M., Li, Z., and Hamm, K.: "Surface spectral albedo intensive operational period at the ARM SGP site in August 2002: Results, analysis, and future plans.", in: Proceedings of the Thirteenth Atmospheric Radiation Measurement (ARM) Program Science Team Meeting, US Department of Energy, Richland, Washington, 2003.

Trishchenko, A. P., Luo, Y., Khlopenkov, K., and Jeong, M. J.: Field Report 3rd Surface Albedo IOP Southern Great Plains (SGP) Cart Site February 8-12, 2004, available at: http://iop.archive.arm.gov/arm-iop-file/2004/sgp/sfcalb-fall/ trishchenko-asd/Report_SurfaceAlbedoIOP_October2004.pdf, 2004a.

Trishchenko, A. P., Luo, Y., Khlopenkov, K., and Cribb, M.: Field Report 4th Surface Albedo IOP Southern Great Plains (SGP) Cart Site October 20-26, 2004, available at: http://iop.archive.arm.gov/arm-iop-file/2004/sgp/sfcalb-winter/ trishchenko-asd/Trishchenko_SrfAlbedo_Feb2004_Report.pdf, 2004b.

Turner, D. D., Tobin, D., Clough, S. A., Brown, P. D., Ellingson, R. G., Mlawer, E. J., Knuteson, R. O., Revercomb, H. E., Shippert, T. R., Smith, W. L., and Shephard, M. W.: The QME AERILBLRTM: A closure experiment for downwelling high spectral resolution infrared radiance, J. Atmos. Sci., 61(22), 2657-2675, 2004.

USDA: Usual planting and harvesting dates for U.S. field crops, United States Department of Agriculture, 1997.

Wittich, K.-P. and Hansing, O.: Area-averaged vegetative cover fraction estimated from satellite data, Int. J. Biometeorol., 38, 209-215, 1995. 